\title{
Measurements of Humidity and Temperature in the Marine Environment during the HEXOS Main Experimenet
}

\author{
K. B. Katsaros, ${ }^{*}$ J. DeCosmo, ${ }^{*}$ R. J. Lind, ${ }^{* 1}$ R. J. ANDERSON, ${ }^{\dagger}$ S. D. SMITH, ${ }^{\dagger}$ R. RRAAN, ${ }^{*} ;$ \\ W. OOST, ${ }^{* *}$ K. UHLIG, ${ }^{\dagger \dagger}$ P. G. MESTAYER, ${ }^{\circledR}$ S. E. LARSEN, ${ }^{*}$ M. H. SMITH, ${ }^{\circ}$ AND G. DE LEEUW \\ * Department of Atmospheric Sciences, University of Washington, Seattle, Washington \\ 'Department of Fisheries and Oceans, Bedford Institute of Oceanography, Dartmouth, Nova Scotia, Canada \\ ** Royal Netherland Meteorological Institute, de Bilt, the Netherlands \\ ${ }^{\text {"H }}$ Abteilung Meteorologie, Institut für Meereskunde, Kiel, Germany \\ - Laboratoire de Mécaniques des Fluides, Ecole Centrale de Nantes, Nantes, France \\ "Rise National Laboratory, Roskilde, Denmark \\ Pure and Applied Physics Department, University of Manchester, Institute of Science and Technology, Manchester, United Kingdom \\ "TNO, Physics and Electronics Laboratory. The Hague, the Netherlands
}

(Manuscript received 6 April 1992, in final form 12 October 1993)

\begin{abstract}
Accurate measurement of fluctuations in temperature and humidity are needed for determination of the surface evaporation rate and the air-sea sensible heat flux using either the eddy correlation or inertial dissipation method for flux calculations. These measurements are difficult to make over the ocean, and are subject to large errors when sensors are exposed to marine air containing spray droplets. All currently available commercial measurement devices for atmospheric humidity require frequent maintenance. Included in the objectives of the Humidity Exchange over the Sea program were testing and comparison of sensors used for measuring both the fluctuating and mean humidity in the marine atmosphere at high wind speeds and development of techniques for the protection of these sensors against contamination by oceanic aerosols. These sensors and droplet removal techniques are described and comparisons between measurements from several differenః systems are discussed in this paper.

To accomplish these goals, participating groups devised and tested three methods of removing sea spray from the sample airstream. The best performance was given by a rotating screen device, the "spray flinger." Several high-frequency temperature and humidity instruments, based on different physical principles, were used in the collaborative field experiment. Temperature and humidity fluctuations were measured with sufficient accuracy inside the spray removal devices using Lyman- $\alpha$ hygrometers and a fast thermocouple psychrometer. Comparison of several types of psychrometers (using electric thermometers) and a Rotronic MP-100 humidity sensor for measuring the mean humidity illustrated the hysteresis of the Rotronic MP-100 device after periods of high relative humidity. Confidence in the readings of the electronic psychrometer was established by in situ calibration with repeated and careful readings of ordinary hand-held Assman psychrometers (based on mercury thermometers). Electronic psychrometers employing platinum resistance thermometers perform very well.
\end{abstract}

\section{Introduction}

Evaporation of water from the world's oceans is one of the most important processes in controlling upper ocean temperature, as surface evaporative cooling largely balances solar heating. This cooling and simultaneous increase in salinity leads to a buoyancy flux in the upper ocean that stimulates vertical motion and mixing in the near-surface waters. In the atmosphere, water vapor is distributed both vertically and

\footnotetext{
${ }^{1}$ Current affiliation: Department of Meteorology, Naval Postgraduate School, Monterey, California.
}

Corresponding author address: Dr. K. B. Katsaros, Department of Atmospheric Sciences, AK-40, University of Washington, Seattle, WA 98195 . horizontally by air currents, and latent heat is eventually released to the atmosphere through condensation during cloud formation and precipitation. This thermal energy is a basic energy source for atmospheric motions. The hydrologic cycle is itself also extremely important for life on earth.

Many water vapor flux data have been collected over land (e.g., Chahuneau et al. 1989), but over the ocean, which represents $73 \%$ of the earth's surface, the difficulties in making these measurements greatly hampered progress (Smith 1989). A few successful studies under low to moderate wind conditions have been reported employing sensors such as Lyman- $\alpha$ hygrometers (Anderson and Smith 1981; Large and Pond 1982; Smith and Anderson 1984) and a refractometer (Kruspe 1977), but no measurements existed at wind speeds above about $14 \mathrm{~m} \mathrm{~s}^{-1}$. Particular difficulties occur over the sea due to detrimental effects of the ac- 


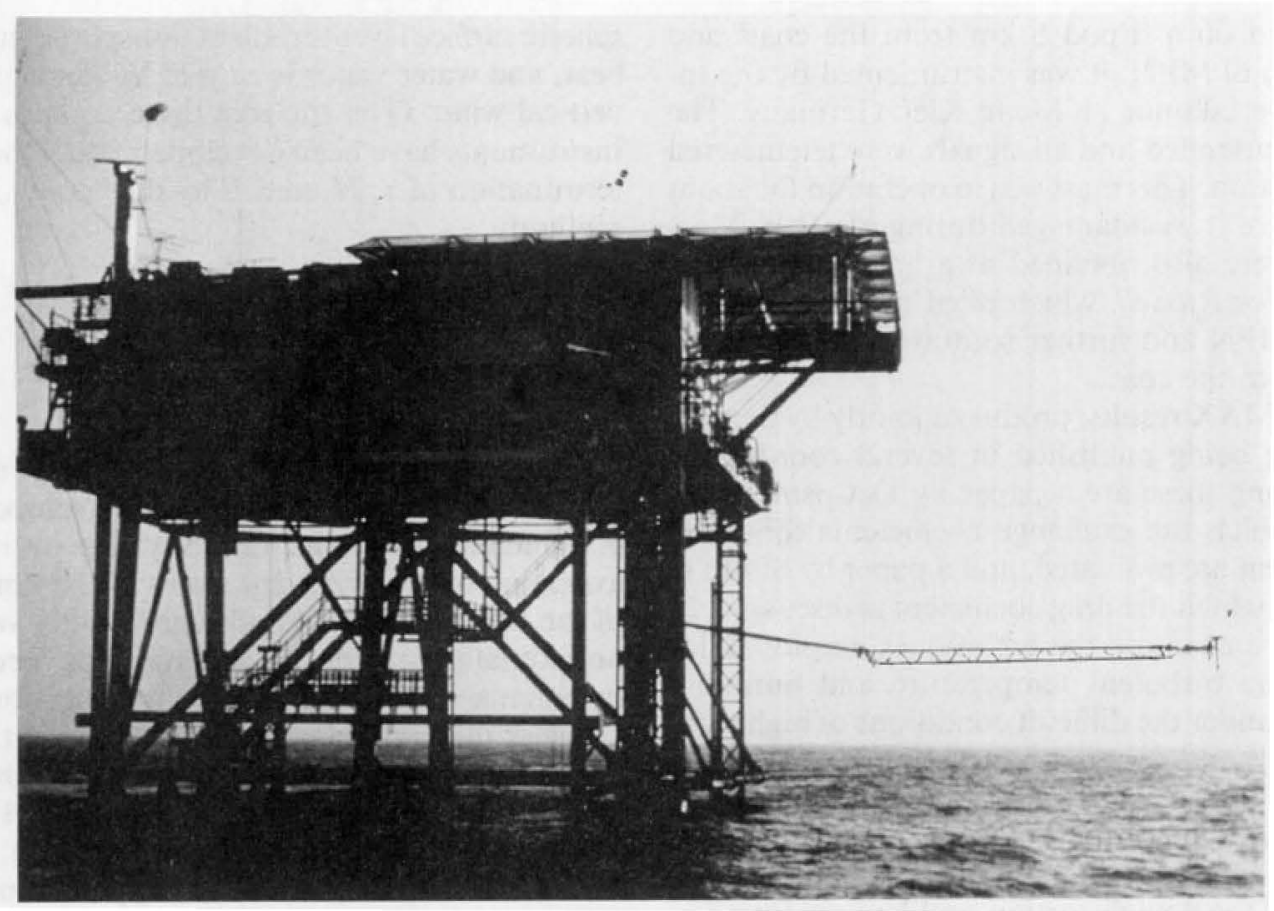

FIG. 1. The Noordwijk research platform (MPN) on the North Sea viewed from the north with the boom mounted on the western face. The helicopter deck of the platform is $20 \mathrm{~m}$ above mean sea level. A mast was erected on its western side above the boom to hold a second set of high-frequency turbulence sensors.

cumulation of salt spray on temperature and humidity sensors (Schmitt et al. 1978).

The great importance of evaporation to both atmospheric and oceanic sciences inspired a group of scientists to organize a new attack on the problem in the early 1980 s. In particular, there was great interest in assessing the potential contribution of sea spray to the water vapor flux at high wind speeds. A pioneering modeling study by Ling and Kao ( 1976) had predicted that the sea-spray contribution to the water vapor and sensible heat fluxes would be significant. Later model calculations also indicated large effects of spray droplets on the fluxes (Bortkovskii 1987; Stramska 1987), but few measurements existed at high enough wind speeds to test these models.

The Humidity Exchange over the Sea (HEXOS) program (Katsaros et al. 1987) was formulated to obtain humidity flux and relevant supporting data over the ocean at moderate to high wind speeds $(>12$ $\mathrm{m} \mathrm{s}^{-1}$ ). Because of the liquid water and salt contamination problems and the delicate nature of many of the temperature and humidity sensors, a decision was made that the field experiment should be carried out on and around a platform large enough to house the scientists and technicians, so that instruments could be monitored, cleaned, or replaced on a regular basis. The experimental program also included measurements taken from a ship, a tripod, and an aircraft.

The early model results were part of our motivation to undertake a major project. However, our analyses of the role of spray in net water flux from sea to air differ substantially from what these models indicate (Edson 1989; Mestayer et al. 1990; Smith et al. 1990; DeCosmo 1991; Rouault et al. 1991), the reasons being, we believe, incorrect model assumptions about the interactions between aerosol distributions and humidity profiles. This is also discussed by Katsaros and DeCosmo (1993) and by DeCosmo et al. (1994) on the basis of HEXOS experimental results and is the subject of continuing additional studies based on the numerical models of Rouault et al. (1991) and Edson (1989).

\section{a. The HEXOS Main Experiment}

The HEXOS Main Experiment (HEXMAX) was carried out on the Dutch research platform Meetpost Noordwijk (MPN), and in its vicinity in October and November 1986 (Smith et al. 1990). Meetpost Noordwijk is a research platform, $15 \mathrm{~m} \times 25 \mathrm{~m}$ in horizontal area, located $9 \mathrm{~km}$ west of the Dutch coast. Turbulence sensors were placed 1) on a boom, which extended 16 $\mathrm{m}$ westward from the edge of the platform and could be set between 6 and $10 \mathrm{~m}$ above mean sea level (Fig. 1), and 2) on a mast on top of the platform at an average elevation of $26 \mathrm{~m}$ above mean sea level (not yet in place in Fig. 1). Mean values of temperature and humidity were collected from a small deck $15 \mathrm{~m}$ above sea level on the northwest corner of MPN. Turbulence and mean measurements were also made from 
a mast placed on a tripod $5 \mathrm{~km}$ from the coast and slightly south of MPN. It was instrumented by the Institut für Meereskunde (If $M$ ) in Kiel, Germany. The mast was unattended and all signals were telemetered to a shore station. This mast was in operation for about 10 days before it was damaged during a storm. Measurements were also obtained at a bow mast on the RRS Frederick Russell, which plied the waters in the vicinity of MPN and further southwest to a distance of $30 \mathrm{~km}$ from the coast.

The HEXMAX results, produced jointly by the participants, are being published in several coordinated papers. Among these are a paper by DeCosmo et al. (1994) in which the exchange coefficients for water vapor and heat are evaluated, and a paper by Smith et al. (1992) in which the drag coefficient is discussed. In this article we examine the techniques employed for measuring the turbulent temperature and humidity fluctuations under the difficult conditions of high wind with sea spray, and describe the experiences of the collaborators in the HEXOS program in obtaining mean temperature and humidity. Details of the measurement of wind velocity and shears on the large platform and evaluation of the flow distortion problem are found in a paper by Oost et al. (1994). The inertial subrange flux calculation method was given special attention in HEXMAX because comparisons could be made to results obtained by eddy correlation (Edson et al. 1991).

\section{b. Theoretical background}

Bulk aerodynamic formulas are often used to calculate the wind stress $\tau$, sensible heat flux $H$, and evaporation $E$ at the sea surface from routine synoptic observations:

$$
\begin{aligned}
\tau & =\rho C_{D}\left(\bar{U}_{z}-\bar{U}_{s}\right)^{2}, \\
H & =-\rho c_{p} C_{H}\left(\bar{U}_{z}-\bar{U}_{s}\right)\left(\bar{T}_{z}-\bar{T}_{s}\right), \\
E & =-\rho C_{E}\left(\bar{U}_{z}-\bar{U}_{s}\right)\left(\bar{q}_{z}-\bar{q}_{s}\right),
\end{aligned}
$$

where $C_{D}, C_{H}$, and $C_{E}$ are the drag coefficient, and Stanton and Dalton numbers, respectively (also called the exchange coefficients for momentum, heat, and water vapor); $\rho$ is atmospheric density; and $c_{p}$ is specific heat at constant pressure. Here, $\bar{U}_{z}, \bar{T}_{z}$, and $\bar{q}_{z}$ are mean wind speed, air temperature, and specific humidity at a reference height $z ; U_{s}, T_{s}$, and $q_{s}$ are the velocity, temperature, and specific humidity, respectively, just above the air-sea interface; $q_{s}$ is usually computed as the saturation humidity at $T_{s}$. The exact origin of these formulas is difficult to trace, but Jacobs (1942) refined the general ideas.

The turbulent fluxes of momentum, heat, and water vapor can thus be estimated from measurements of mean quantities once the values of the exchange coefficients are established. To that end the left-hand side of Eqs. (1)-(3) must be measured together with the mean quantities on the right-hand side. In the atmo- spheric surface layer turbulent transport of momentım, heat, and water vapor is carried by fluctuations of the vertical wind. Over the past three decades specialized instruments have been developed that allow direct determination of $\tau, H$, and $E$ by the "eddy correlation" method:

$$
\begin{aligned}
\tau & =-\rho \overline{w^{\prime} u^{\prime}}, \\
H & =\rho c_{p} \overline{w^{\prime} T^{\prime}}, \\
E & =\rho \overline{w^{\prime} q^{\prime}},
\end{aligned}
$$

where $u^{\prime}$ and $w^{\prime}$ are fluctuating downwind and vertical velocity components, $T^{\prime}$ is fluctuating temperature, and $q^{\prime}$ is fluctuating specific humidity. The overbar implies averaging over all relevant scales of the time variation of the fluxes. These formulas are strictly valid only in horizontally homogeneous conditions, and when the turbulence statistics are stationary (e.g., Busch 1972).

Other methods to estimate the turbulent fluxes near the earth's surface include the profile method and the inertial-dissipation method (e.g., Blanc 1985, 1987; Fairall and Larsen 1986; Edson et al. 1991). The profile method has recently found less application because of the difficulties in keeping instruments at different elevations well intercalibrated, particularly over the ccean where there are very small differences in $\bar{T}$ and $\bar{q}$ over a feasible range of heights above the wave crests. Another difficulty with estimating fluxes from the slope of the profile is the modification of the profile just above the air-sea interface by surface waves (e.g., Hasse et al. 1978). The influence of the waves decays exponentially with height.

The inertial-dissipation method is of great interest for oceanic measurements because it is less sensitive to platform motion than the eddy correlation method. As the eddy correlation method, it requires high-frequency response sensors. In the framework of HEXOS, the HEXIST group (HEXOS experiments in the simulation tunnel) specifically concentrated on this method during HEXMAX (Fairall et al. 1990).

\section{c. Experimental difficulties}

Many early surface flux measurements over the oceans have had to be discarded because of salt-contaminated temperature measurements (Schmitt et al. 1978). The salt contamination problem may be explained as follows. Lowered vapor pressure above salt solutions, described by Raoult's law, allows an aqueous sea-salt solution to be in equilibrium with its environment in air unsaturated with respect to a pure water surface. Below $60 \%$ relative humidity (RH), pure $(\mathrm{NaCl})$ salt is in equilibrium with the surrounding air when in a crystalline state, while above $85 \% \mathrm{RH}$, it is in equilibrium when in a liquid state (the salinity of the equilibrium liquid depends on the humidity). For relative humidities between $60 \%$ and $85 \%$, which are typical of the marine environment, the amounts of 
aqueous salt solutions and crystalline salt on a contaminated sensor are constantly changing with fluctuations in relative humidity. Following a step decrease in humidity, evaporation cools the sensor (producing a "cold spike" in the data). When the relative humidity increases, deliquescence warms the sensor (creating a "warm spike"). Both of these processes add spurious variance to the time series of temperature. The indicated temperature has in effect a lagged response to the rate of change of humidity, which is nearly impossible to remove since the amount of contamination can change during a data run. Friehe (1991, personal communication ) suggests that there are no significant errors in mean temperatures from sensors covered with salt spray under steady-state conditions. After averaging over a sufficient length of time, "warm" and "cold" spikes tend to cancel each other so that mean values of dry-bulb temperatures from salt-encrusted sensors on buoys and ships can be considered accurate when conditions are nearly stationary. In a recent article, Hartmann et al. (1990) discusses correcting contaminated temperature sensors by simultaneous humidity measurements.

Similarly, extreme difficulties in evaluating atmospheric humidity over the ocean are also caused by the presence of sea-salt aerosols. We avoid the salt contamination of temperature and humidity sensors by the use of aspirators.

\section{Methods}

HEXMAX participants developed techniques to remove spray droplets from the airstream before temperature and humidity were measured to avoid the problems due to salt contamination described above. Since temperature and humidity measurements are difficult to make in general, and the spray-removal devices make additional corrections necessary, a general philosophy of the project was to duplicate measurements by different techniques, when possible, to provide redundant estimates of all the fluxes and mean quantities. Much effort was expended on intercomparisons between different datasets and the different flux evaluation procedures (e.g., Edson et al. 1991; DeCosmo et al. 1994; Smith et al. 1992).

The mechanical anemometers used during HEXMAX included a K-Gill unit (Ataktürk and Katsaros 1989), a pressure anemometer (Oost et al. 1991), and the If M 3D propeller system, all of which are not affected by sea spray. Two sonic anemometers were also deployed on MPN, one on the boom and one on top of the mast. Spikes have been observed on the output signal of the boom sonic anemometer when the sensing heads were struck by rain or sea-salt aerosols, while the only problem with the sonic anemometer on the mast occurred during periods of intense fog when water stuck on the transducers. These sensors recover immediately after the water evaporates.
In this section we describe the spray-removal techniques and the high- and low-frequency sensors used for temperature and humidity measurements. Tests of their performance are found in section 3 .

\section{a. Spray-removal techniques}

\section{1) THE UNIVERSITY OF WASHINGTON "SPRAY FLINGER"}

The University of Washington (UW) "spray flinger" (Fig. 2) was designed to minimize flow modification on scales important to the eddy correlation calculations employing data from temperature and humidity sensors inside the housing. The design also ensured that the droplets removed from the airstream did not remain on the walls of the housing or filter where they could evaporate and affect the measurements. Tests were made to ensure that there were no thermal effects due to the device. The housing is manually directed upwind, which was not problematic for HEXMAX since the boom was raised every few hours for adjustment and maintenance of the sensors. The spray flinger is a 60 $\mathrm{cm}$-long tube, $10 \mathrm{~cm}$ in diameter, with a rotating filter screen and fan on the upwind end, and an exit fan and the motor at the downwind end. The filter is a single layer of nylon stocking, which is highly nonabsorbing, supported by a wire mesh. Particles and droplets are intercepted by the rotating filter and flung aside, out of the airstream entering the tube. The rotation rate of the filter is about $625 \mathrm{rpm}$. Inspection of the filter revealed that this rate of rotation prevented buildup of water or salt. The nylon filter was replaced at weekly intervals.
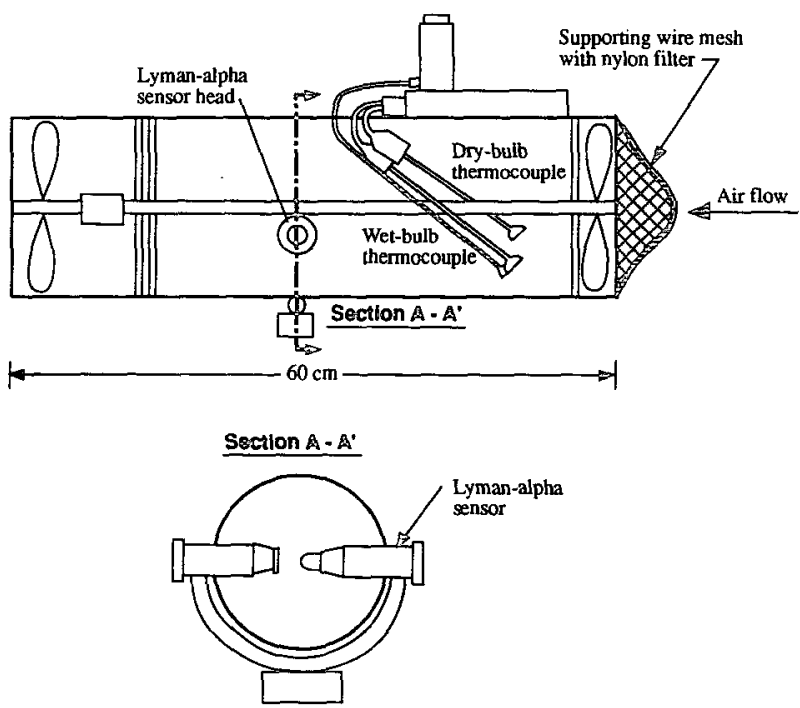

FIG . 2. Sketch of aspirated protective housing, "the spray flinger," used for the protection of the thermocouple psychrometer and the Lyman- $\alpha$ hygrometer by the University of Washington group. The system is manually directed upwind. 


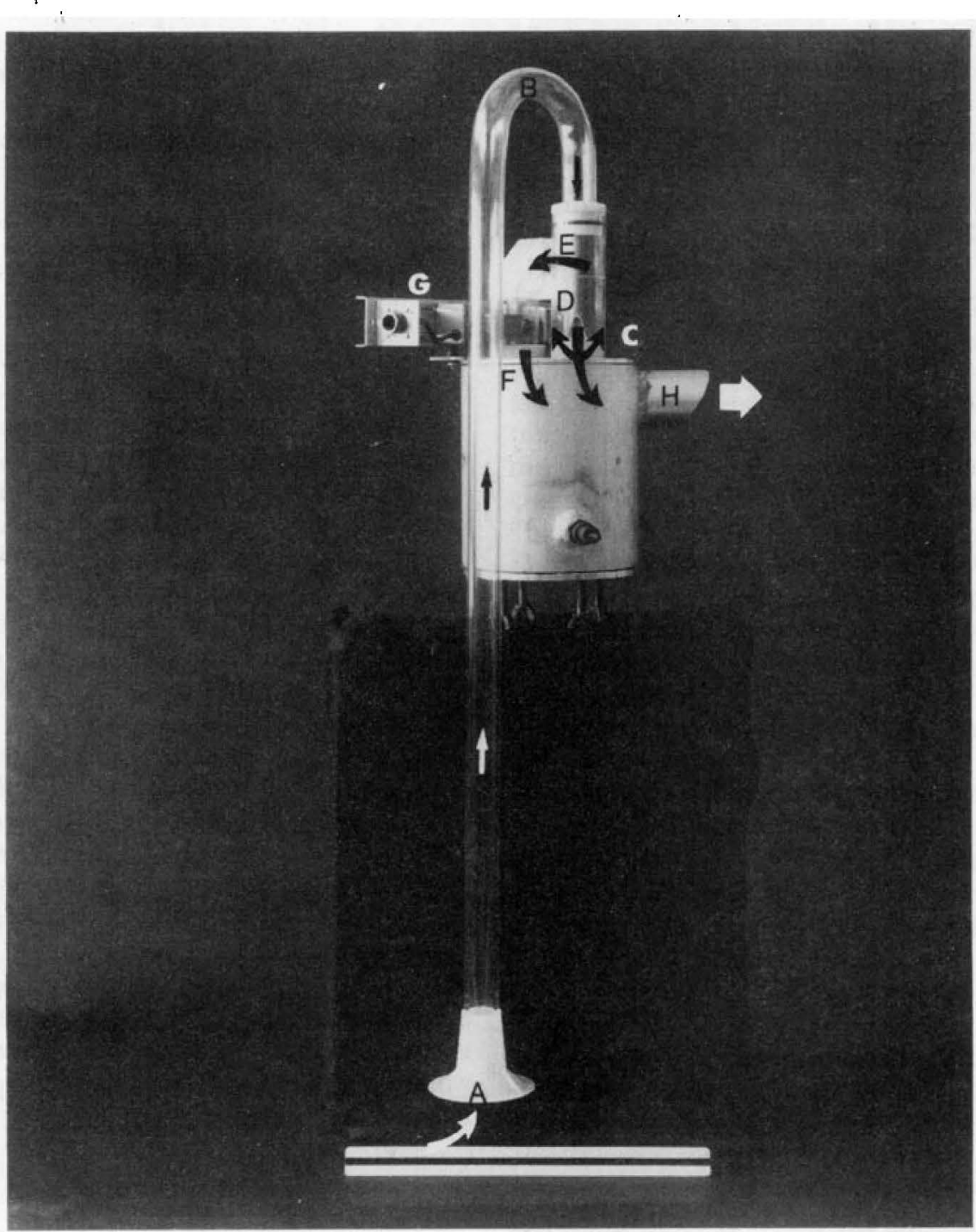

FIG. 3. The Bedford Institute of Oceanography spray remover, "the refinery."

Although there is a slow draw of air through the unit by the upwind and exit fans $\left(1-2 \mathrm{~m} \mathrm{~s}^{-1}\right)$, it is mainly a passive device with respect to the airflow. Inside, wet and dry thermocouples and a Lyman- $\alpha$ hygrometer sample the air for mean and fluctuating temperature and humidity. Wind tunnel and field tests showed the airflow inside the unit to be steady with about one-half the ambient wind speed for wind directions less than $40^{\circ}$ off the axis. Even in low wind speeds there is adequate ventilation for the wet-bulb sensor. Comparison showed that data from shielded and unshielded thermocouples (respectively, inside and outside the spray flinger) are not noticeably affected by the housing within the sensitivity of our temperature and humidity sensors. Thus, there are no thermodynamic effects induced by the spray flinger, except possibly in sunny, low wind speed conditions, when warming may occur due to radiation on the tube.
A quantitative test of the effectiveness of the spray flinger in removing aerosols from the sample airstream was performed during HEXMAX using a Knollenberg optical particle counter (CSAS $100 \mathrm{HV}$ ) to measure the aerosol content with diameters between 0.5 and 32 $\mu \mathrm{m}$ in the environmental air and at the rear of the spray flinger (see section 3 ).

\section{2) THE BEDFORD INSTITUTE OF OCEANOGRAPHY "REFINERY"}

Participants from the Bedford Institute of Oceanography (BIO) employed a flow separation method similar to devices used in humidity sensors on airplanes. This device was nicknamed the "refinery." The BIO aspirator (Fig. 3) works as follows: air is drawn up into an inverted funnel (A) to exclude rain and large droplets. The funnel is on a tube that extends 
slightly below the boom to reduce the distance between the humidity and vertical wind (sonic anemometer) sensors. The inlet tube has a $180^{\circ}$ bend $(B)$ and the airflow impinges downward on an impact target (C) where droplets are collected. Most of the airflow then passes upward through an outer tube $(D)$ concentric with the inlet tube and is directed out a side outlet $(E)$ through the sampling path (F) of the Lyman- $\alpha$ hygrometer $(G)$ and exits through a suction fan ( $\mathrm{H}$ ). Some of the air is bled from the droplet impact target directly into the fan to remove collected water. A small hole drilled near the sensing path allows a microthermistor to be inserted for measurement of temperature fluctuations. Two aspirators were built, differing mainly in the capacity of the suction fan; the smaller fan was found to be adequate. Measurements by identical sensors inside and outside the device show that the flow through the unit is slow enough that no thermodynamic heating effect is detectable.

The aspirator was built mainly of clear acrylic plastic so that it could be visually inspected for accumulation of water droplets. Preliminary tests were carried out to select a fan speed that resulted in few droplets passing through to the sensing path of the hygrometer. With this aspirator it was possible to continue taking humidity flux measurements in conditions of light rain, high winds (with spray droplets), or high humidity, in which a bare Lyman- $\alpha$ humidiometer would quickly become contaminated. However, data still could not be taken in periods of heavy or prolonged rain. Droplets tended to impact on the $180^{\circ}$ bend and when this happened the humidity signal remained high until the drops had evaporated, resulting in periods of up to a few minutes with erroneous humidity data. During MEXMAX, this problem arose mainly when the boom was raised for maintenance, pointing the inlet funnel into the wind.

\section{3) THE KONINKLIK NEDERLANDS METEOROLOGISCHES INSTITUT "CYCLONE"}

The group from Koninklijk Nederlands Meteorologisch Institut (KNMI) employed a vortex method. The incoming air was forced into a helical motion, which removed the aerosols by centrifugal forces. This spray remover was called "the cyclone." Unfortunately, although the principle was promising, collected water sometimes accidentally contaminated the sensors and the data were not usable much of the time.

\section{4) ¿NSTITUT FÜR MEERESKUNDE PROTECTIVE HOUSING}

The Kiel group mounted their psychrometer on a wind vane; it was contained in a specialized meteorological housing (Fig. 4) with forced ventilation of at least $4 \mathrm{~m} \mathrm{~s}^{-1}$. It was therefore protected from direct radiation and rain. A screen made of an inert material
(Perlone), with a mesh size of $0.5 \mathrm{~mm}$, covered the entrance to the housing to reduce the influence of sea spray. Contamination of the inert mesh would not influence the humidity measurements inside the housing since a rather large volume of air flows through.

\section{5) TNO PROTECTIVE HOUSING}

A capacitance hygrometer used by the TNO Physics and Electronics Laboratory for profiling mean humidity very near the sea surface was mounted in a $30-\mathrm{cm}-$ long and $10-\mathrm{cm}$-diameter protective tube with forced aspiration. The flow rate was rather low for these measurements of mean relative humidity. The tube was mounted vertically, thus effectively protecting the sensitive element from pollution by impacting spray droplets advected by the horizontal wind. Without this protective tube, erroneous measurements occurred in the course of almost every profile, as detected from spurious results and unexplained differences between successively measured top-down and bottom-up profiles. In the shielded configuration the profiles usually were more consistent. Some results were presented by de Leeuw (1989, 1990).

\section{b. High-frequency humidity measurements}

Meteorological humidity measuring techniques are reviewed by Schmugge and Andre (1991). Here we discuss only the methods employed in HEXMAX. Instruments based on two principles were employed; one principle was the varying intensity of absorption of radiation in the Lyman- $\alpha$ absorption line, due to fluctuating water vapor concentration (e.g., Tillman 1991), and the second one was psychrometry (e.g., Hay 1980; Shaw and Tillman 1980; Tsukamoto 1986).

\section{1) LYMAN- $\alpha$ HYGROMETERS}

Two commercially available Lyman- $\alpha$ hygrometers were used: the Electromagnetic Research Corporation (ERC) instrument (used by BIO and $\mathrm{KNMI}$ ), and the Atmospheric Instrumentation Research, Inc. (AIR) hygrometer (used by UW). In addition, two specially designed instruments were operated by the HEXIST group to measure the inertial subrange of the humidity spectra. The first of these used the same optical components as ERC instruments, from Glass Technologists, Inc., set in an open tuning-fork-like slender support designed by C. W. Fairall at The Pennsylvania State University (PSU) to minimize small scale flow perturbations. Its low-noise electronic circuits were built at Risø National Laboratory and set on the support itself to minimize noise. Using the calibration method of Buck (1985) the instrument was found to keep a remarkably stable calibration for the humidity fluctuations during the entire experiment (Fairall et al. 1990). The second one was developed in cooperation by the Institut de Mécanique Statistique de la Turbu- 
lence (IMST), the Service d'Aéronomie du CNRS (SA), and Risø National Laboratory. The IMST-SARisø instrument has special optics: the high-power ultraviolet source emits a highly collimated beam, and the detector is an ultraviolet photomultiplier connected to an ultralow-noise electrometer. To minimize electromagnetic noise, the optical and electronic components are sealed in the same aluminum casing as the fork-shaped support (Mestayer et al. 1989).

ERC instruments were housed in the "refinery" and in the "cyclone" and the AIR version in the "spray flinger." The two instruments of the HEXIST group were operated fully exposed to the airstream, the PSURis $\emptyset$ instrument on top of the mast, and the IMSTSA-Risø instrument on the boom. During periods of fine weather one of BIO's ERC instruments was also operated bare.

\section{2) THERMOCOUPLE PSYCHROMETERS}

The UW employed a pair of wet- and dry-bulb finewire thermocouples made of chromel constantan (type E, 25- and $50-\mu \mathrm{m}$ diameter for the dry-bulb sensors and $50 \mu \mathrm{m}$ for the wet-bulb ones) as a psychrometer inside the spray flinger (Fig. 2). Continuous moistening of the wet bulb was achieved by a small reservoir and plumbing system that provided a flow of water to the bottom end of the wick; capillary action kept the cotton wick thoroughly wetted. The wet-bulb thermocouple sensors were frequently rinsed or replaced.

It is usually preferable to assemble the wet bulb so that the wicking moves the water vertically upward rather than allowing it to travel down past the temperature sensor from above. We have found with the very small thermocouple sensors that the water temperature in the container vessel may be different from the wet-bulb temperature of the air and can therefore cause erroneous readings (warm spikes as drops pass the thermocouple junction ) if the flow is from above and too fast.

Psychrometry was also employed by the If $M$. Their psychrometer consisted of type E dry- and wet-bulb thermocouples. In this device the cotton wick of the wet bulb is wetted indirectly: distilled water is pumped up by a peristaltic pump at a slow rate. It then runs down a cotton string. The wet bulb is wetted by a tiny bypass from the main string (see Fig. 4). Surplus water may drop off from the main cotton string without influencing the wet-bulb measurements. The forced slow supply of distilled water provides for a continuous, slow flushing of the cotton wick keeping salt from collecting on it. At the same time, the water supply is exposed to the airstream and adjusted to equilibrium temperature before reaching the wet bulb.

\section{3) CARBON-FILM HYGRISTOR, THE HICUP}

During the HEXOS project a prototype hygrometer, acronym HICUP, was operated by the UMIST (Uni-

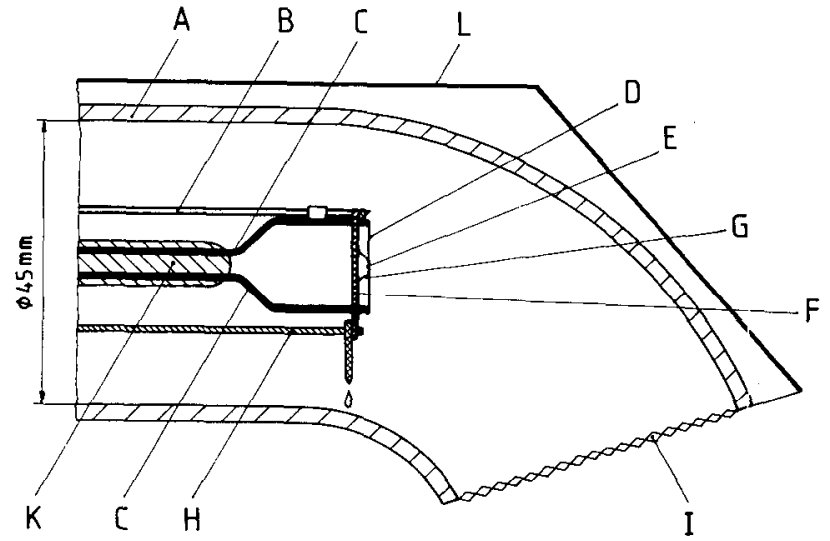

FIG. 4. Sketch of the Institut für Meereskunde's thermocouple psychrometer in its aspirated housing: A-housing, B-water supply tube, $\mathrm{C}$-thermocouple support, 1-mm diameter, $\mathrm{D}$-thermocouple wires, 100- $\mu \mathrm{m}$ diameter, $\mathrm{E}$ - thermocouple junction, $\mathrm{F}$-cotton wick, $\mathrm{G}$-cotton thread of wet-bulb thermocouple, $\mathrm{H}$-support for wick, I-nylon mesh, $\mathrm{K}$-ceramic support, and L-radiation shield.

versity of Manchester Institute of Science and Technology) group on board RRS Frederick Russell in order to evaluate its performance under harsh marine weather conditions. This device was originally developed for measuring total water mixing ratio under cloudy conditions to an accuracy of about $0.05 \mathrm{ppm}$ at frequencies of up to $10 \mathrm{~Hz}$. It exploits the fast response of carbon-film hygristors and overcomes the problems of drift associated with this type of sensor by periodic autocalibration using controlled humidifiers. Air drawn into the hygristor housing is brought into thermal equilibrium with the sensor element before being passed over it; the temperature of this housing is controlled to maintain the relative humidity at the sensor between about $30 \%$ and $50 \%$ in order to optimize its response time and resolution. The hygristor is ventilated at about $25 \mathrm{~m} \mathrm{~s}^{-1}$, which gives a response time approaching $0.1 \mathrm{~s}$ for sensor temperatures above $0^{\circ} \mathrm{C}$. Long-term drift in the sensor characteristics is corrected by periodic autocalibration, for which two reference sources of saturated air are maintained by means of thermoelectric heat pumps, with dewpoint temperatures spanning ambient values encountered by the hygristor. Thus, the role of the hygristor is reduced to one of interpolation between the reference values. This instrument proved to be relatively insensitive to salt contamination, assisted by the warming resulting from the nonoptimized sampling techniques adopted. HICUP was not developed specifically for this application and, for a future field program of this type, much could be done to optimize its operation to provide data at higher sampling rates and in a form more amenable to subsequent processing.

\section{c. Low-frequency humidity measurements}

Cooled mirror dewpoint hygrometers (e.g., Coantic and Friehe 1980) had been included in the HEX.MAX 
plan to provide mean humidity measurements because they are absolute instruments. Several were tried, but no special precautions were taken for operating these sensors in the marine environment and none operated well. A lithium chloride dewpoint sensor also did not perform well in the marine environment; it required thorough drying in the laboratory after each rainy period. Since these instruments failed, slow-response psychrometry was substituted for all mean humidity estimates.

\section{1) RESISTANCE THERMOMETER PSYCHROMETER}

The sensors operated by UW on MPN were stainless steel encased platinum resistance thermometers housed in ventilated cylindrical shields. A water reservoir was hung below the wet bulb with a $10-\mathrm{cm}$-long wick drawing water onto the sensor from below. The wet-bulb arrangement was rigged on site and natural ventilation by the typically strong winds during HEXMAX was found to be sufficient.

If $M$ used a slow-response, double radiation-shielded psychrometer with platinum resistance thermometers at the tripod for measurement of mean humidity and temperature. The fast-response psychrometer at the tripod could also be used to measure mean humidity.

If these large wet bulbs collect salt on them over time the relative humidity may be in error. This is not a concern in short-term experiments. A salt solution of $3.6 \%$ on the wet bulb would result in approximately a $2 \%$ overestimate of the relative humidity.

\section{2) ROTRONIC HUMIDITY SENSOR}

The synoptic weather station on MPN, operated by KNMI, included a Rotronic MP-100 hygrometer that is based on the principle of capacitance change as the small transducer absorbs and desorbs water vapor. To avoid contamination of the detector, special filters cover the sensor. Van der Meulen (1988) discusses these filters, especially their effect on time response of the sensor, and the importance of keeping the filters clean. Dirty filters (salt or other contaminants) may completely mask the atmospheric effects. Even the oil from the touch of a human hand is detrimental.

The UW electronic psychrometer and the Rotronic MP-100 of the Dutch Meteorological Service unit were mounted within a meter of each other on the instrument deck at the northwest corner of the platform. At regular intervals several types of hand-held psychrometers were read next to the electronic ones as a calibration check, and also at other positions around MPN to test for effects of flow distortion and heating by the platform.

\section{3) VAISAla HUMICAP}

The Vaisala HUMICAP capacitance hygrometer operated by TNO for mean profile measurements near the surface in support of the aerosol profiles (de Leeuw 1990 ), is based on an operational principle similar to the Rotronic. However, the sensor was only covered by a small cagelike protective cap provided by the manufacturer. This was not adequate to prevent impaction of sea spray, particularly near the air-sea interface. Additional protection against sea-salt contamination was provided by the TNO protective housing described above. The HUMICAP was calibrated versus the KNMI Rotronic before and after each profile measurement.

\section{d. High-frequency temperature measurements}

Techniques for high-frequency temperature measurements were reviewed by Larsen et al. 1980 .

\section{1) Thermocouple temperature}

Several types of electronic temperature sensors were employed. The University of Washington employed a $25-\mu \mathrm{m}$-diameter thermocouple inside the spray flinger (Fig. 2) to obtain temperature fluctuations. It was rinsed or replaced regularly, but effects of salt contamination were nonetheless evident after long exposure (see section 3d for details).

The Institut für Meereskunde also employed thermocouples for temperature inside their shield (Fig. 4); however, effects of salt contamination were such that these data were not used in the final analysis.

\section{2) THERMISTOR}

Two types of thermistors were used by the BIO group to measure air temperature: microbead thermistors (Victory Engineering Corporation, model E41A401) and Fastip thermistors (Thermometrics, model FP07), both of which have a time constant of $0.1 \mathrm{~s}$ in still air and less in moving air. Both are very stable; Fastips are routinely used to measure water temperature with accuracy and resolution of $0.01^{\circ} \mathrm{C}$. A linearizing bridge circuit developed for oceanographic turbulence and mean temperature measurements (Oakey and Anderson 1986, personal communication) was adapted for use in the marine atmosphere. The Fastip is sealed in glass and waterproof, while the microbead thermistors have exposed leads. In spite of occasional rinsing with freshwater, many of the microbead spectra showed evidence of salt contamination and sensitivity to time derivatives of humidity.

\section{3) COLD-Wire THERMOMETER}

The HEXIST group, which specialized in high-frequency devices for dissipation measurements of surface fluxes, used a cold-wire thermometer, that is, a platinum resistance probe $1 \mu \mathrm{m}$ in diameter operated in an ultralow-noise bridge designed by T. Deaton to obtain an effective frequency response larger than $1 \mathrm{kHz}$. 


\section{4) SONIC TEMPERATURE}

A noncontact method for measuring high-frequency temperature fluctuations in the marine environment was also tried in HEXMAX. The travel time of sound is used in the sonic anemometer to measure turbulent fluctuations of atmospheric density, which is related to temperature with additional corrections for humidity effects and for the effect of wind velocity on sound travel time (Larsen et al. 1993). The temperature from both the sonic on the boom and the sonic on the mast at the top of the platform were used for this purpose.

\section{e. Low-frequency temperature measurements}

Mean temperature was provided by an R. M. Young resistance thermometer and the hand-held psychrometers on MPN and similarly by the resistance thermometer of the psychrometer on the tripod. Such sensors are reviewed by Deacon (1980). The temperature sensors are fairly large, of order 5-mm diameter, and thus the radiation shield and ventilation are important aspects of how well these measurements represent the atmospheric temperature. The platinum resistance thermometers of the psychrometer operated by UW were in a tubular radiation shield provided by the R. $M$. Young Company; motor-driven suction provided a 3 $\mathrm{m} \mathrm{s}^{-1}$ airflow past the sensors. In the late fall for conditions at $54^{\circ} \mathrm{N}$ this protection was found to be entirely adequate. $^{2}$ The Fastip thermistors, mounted under small ( $2.5 \mathrm{~cm}$ in diameter) hats for radiation shielding, were also used for mean temperature and are believed to be accurate in this configuration to $0.1^{\circ} \mathrm{C}$. Handheld psychrometers for in situ calibrations included aspirated mercury-in-glass thermometers measuring wet- and dry-bulb temperatures (by the Keiko Co.) and aspirated resistance thermometers (Jenway Co.). Mean temperatures at the sea surface and on the mast were measured with thermistors YSI type 46040; the sensor on the mast was in a ventilated housing. On the If $\mathrm{M}$ tripod, mean temperatures were measured by the dry-bulb thermocouple of the fast response psychrometer and the 5-mm-diameter platinum resistance thermometer, the dry-bulb thermometer of the slow-response psychrometer. The typical accuracy of the latter thermometer is better than $0.1^{\circ} \mathrm{C}$.

\section{Results}

\section{a. Spray-removal techniques}

A field test of the effectiveness of the spray flinger in removing droplets from the airstream was performed by sampling the airstream using a Knollenberg optical particle counter with and without the spray flinger act-

\footnotetext{
${ }^{2}$ When operating this sensor on Lake Washington in the summertime (at $48^{\circ} \mathrm{N}$ ), we found that on clear days with low winds ( $<3$ $\mathrm{m} \mathrm{s}^{-1}$ ) overheating may occur.
}

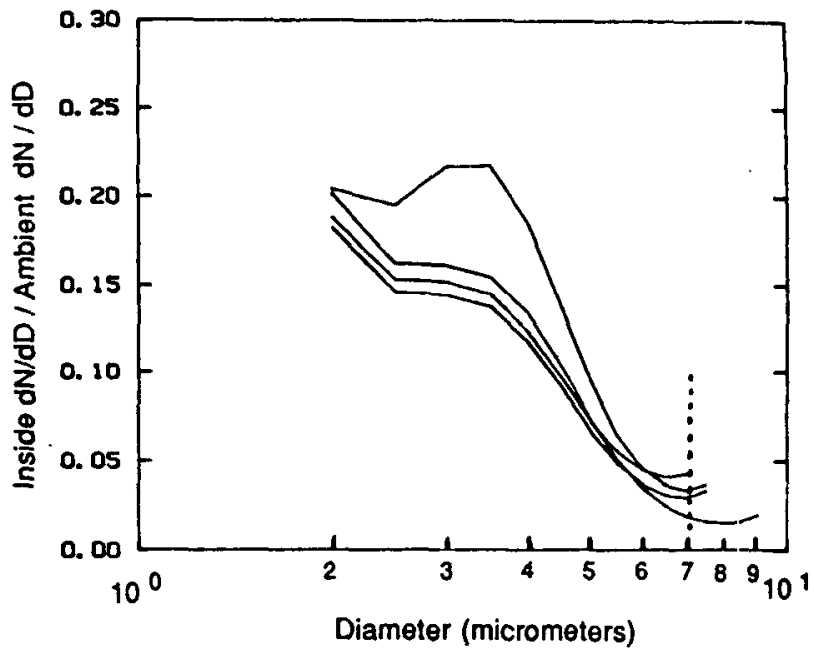

FiG. 5. Ratio of number density of particles with spray flinger ahead of intake tube to open intake tube vs particle diameter in micrometers for four different 45-min periods on 24 November 1986. Differences between the curves illustrate natural variability over the entire sampling period, as well as the uncertainty in the measurements.

ing as a filter in front of the intake tube. The results for four 45-min periods are shown in Fig. 5. About $80 \%$ of the droplets larger than $2 \mu \mathrm{m}$ in diameter, and all particles larger than $10 \mu \mathrm{m}$ in diameter, are removed from the sample airstream by the spray flinger. These results show that the droplet removal system is effective, and it does not interfere unduly with the turbulence measurements of temperature and water vapor density. However, even though the majority of the hydrometeors were eliminated from the sample airstream, a slow accumulation of salt on the thermocouples was noticed during the data collection period. This accumulation may have occurred during the nonoptimal orientation of the housing whenever the boom was raised for maintenance. The temperature sensors were replaced as frequently as possible, and data for which salt contamination was apparent were not included in the analysis. We had found during the HEXOS pilot experiment of 1984 (Katsaros et al. 1987) that replacement of temperature sensors was better than attempting to clean them by rinsing.

The protective aspiration devices degrade high-frequency response to varying degrees by mixing incoming air as it enters the housings; this will be illustrated by comparing humidity spectra in the following section. In addition finite delays are introduced as air passes from the housing inlet to the sensor. Significant cospectral phase shifts were seen between signals from collocated bare and aspirated BIO Lyman- $\alpha$ hygrometers. High-frequency humidity fluctuations detected by the bare Lyman- $\alpha$ were sensed by the aspirated hygrometer as much as $720^{\circ}$ of phase later as the air passed through the tubing of the aspirator (Fig 6a). From phase-shift analyses, time delays were found to 

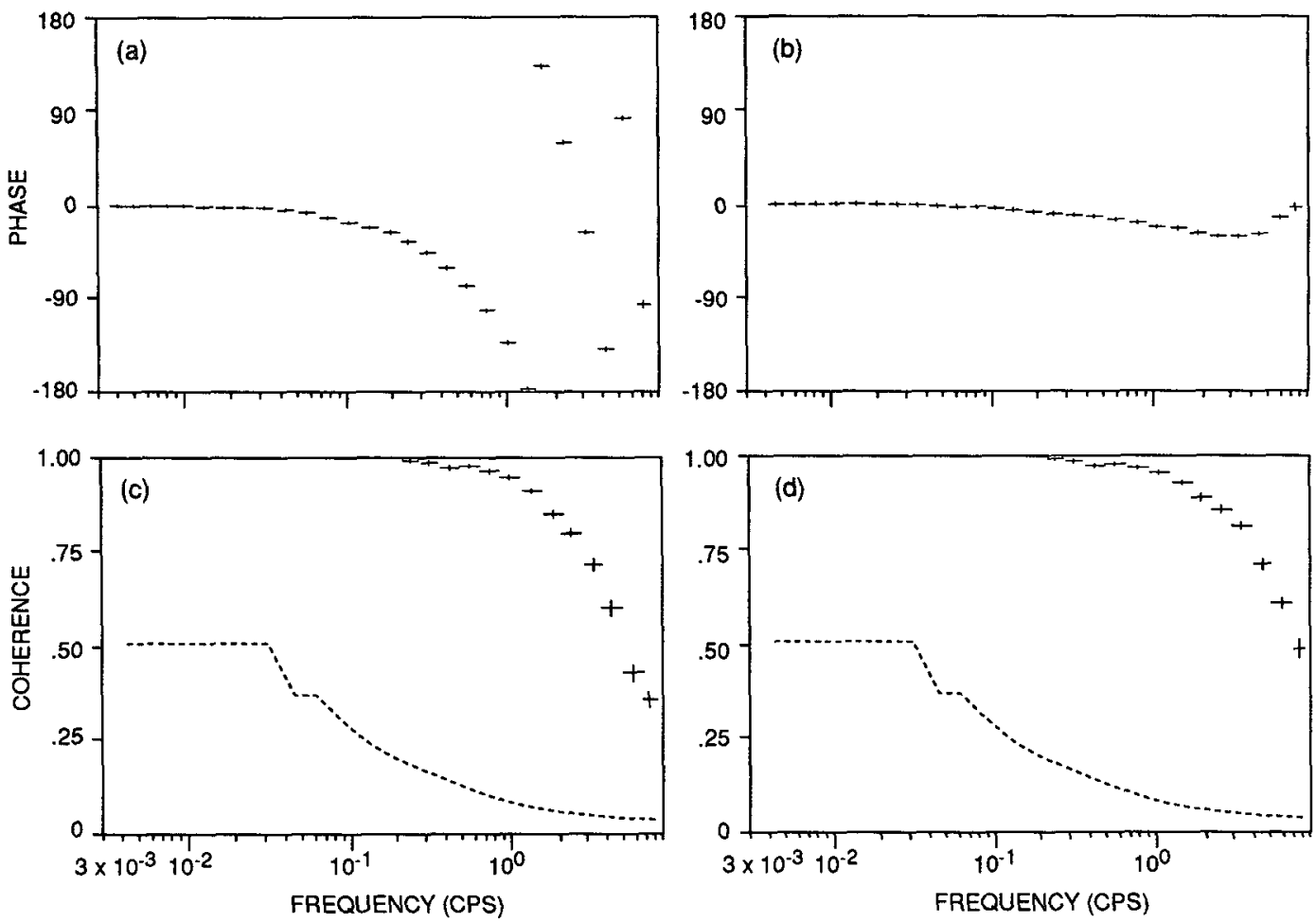

FIG. 6. Phase and coherence plots of the bare vs aspirated BIO Lyman- $\alpha$ humidiometers. (a) and (c) Data as recorded in the field; (b) and (d) same data after correction for aspirator delay. The dashed line indicates the $95 \%$ confidence limit.

be 0.38 and $0.25 \mathrm{~s}$, respectively, for the small and large BIO aspirators (the difference was due to the capacity of the fan, not the length of tubing), and $0.31 \mathrm{~s}$ for the KNMI cyclotron aspirator. In the BIO analysis, data from the aspirated sensors were advanced in time to compensate for the time lag introduced by the housing.

The aspiration of the UW spray flinger was dependent on the ambient wind. Wind tunnel tests showed that the speed of the air flowing through the housing was roughly half the ambient wind speed up to $10 \mathrm{~m} \mathrm{~s}^{-1}$ and a third of the wind speed at $16 \mathrm{~m} \mathrm{~s}^{-1}$ as illustrated in Fig. 7. The wind speed inside the spray flinger was sensed with a Pitot tube. With the small distances required to reach the thermocouples and Lyman- $\alpha$ hygrometer (see Fig. 2), time delays introduced by the housing in $10 \mathrm{~m} \mathrm{~s}^{-1}$ winds were less than $0.036 \mathrm{~s}$. Signals were sampled at $27 \mathrm{~Hz}$ after low-pass filtering at $7 \mathrm{~Hz}$. Time-lag corrections were necessary for the Lyman- $\alpha$ signal for wind speeds below $8.5 \mathrm{~m} \mathrm{~s}^{-1}$; timelag corrections for the psychrometer, located $10 \mathrm{~cm}$ from the filter, were not necessary since all analyzed data were at wind speeds above $6 \mathrm{~m} \mathrm{~s}^{-1}$.

Figure 8 illustrates the relative response of the BIO bare Lyman- $\alpha$ hygrometer and the one inside the spray flinger. This shows that more than $90 \%$ of the humidity signal was retained to frequencies of about $6 \mathrm{~Hz}$. Covariance $\left(q^{\prime} w^{\prime}\right.$ and $\left.T^{\prime} w^{\prime}\right)$ spectra calculated for flux de- termination by the eddy correlation method and autospectra of $q^{\prime}$ or $T^{\prime}$ employed for the inertial subrange method, illustrate that this frequency response is sufficient for the flux estimations under all conditions en-

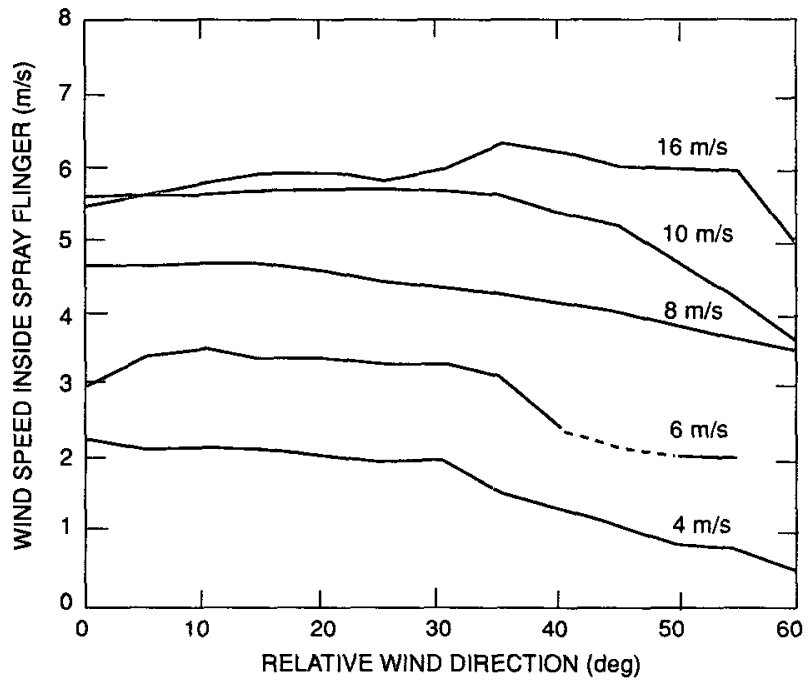

FIG. 7. Results of wind tunnel tests of the UW spray flinger. Wind speed measured inside the spray flinger vs wind direction for five different tunnel wind speeds (marked on the curves). 


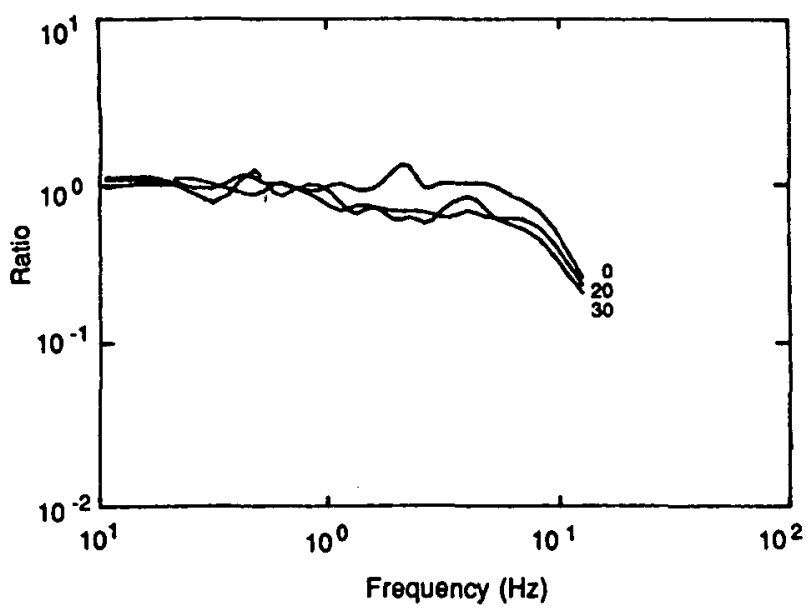

FIG. 8. Ratio of spectral energy density of University of Washington's Lyman- $\alpha$ hygrometer inside the spray flinger to the Bedford Institute of Oceanography's Lyman- $\alpha$ sensor exposed to the ambient air vs frequency. Spectral energy densities were calculated from simultaneously recorded time series of both instruments for mean wind vector $0^{\circ}, 20^{\circ}$, and $30^{\circ}$ off aspirator axis. Wind speed for these data was $10 \mathrm{~m} \mathrm{~s}^{-1}$. The data were filtered with a $7-\mathrm{Hz}$ low-pass filter. The time series begin to diverge at $1 \mathrm{~Hz}$ for off-axis wind, and are a factor of two low at the highest frequency resolved by this flux-measuring system $(4 \mathrm{~Hz})$. At least $90 \%$ of the flux occurs at frequencies less than $1 \mathrm{~Hz}$.

countered in HEXMAX. Even $1 \mathrm{~Hz}$ was adequate for the eddy correlation method (DeCosmo et al. 1994). The spray flinger was the most successful of the three aspirator housings in that it introduced less lag and spectral attenuation (see following section) so corrections to eddy flux calculations were minimal, and it protected the sensors as least as well as the others.

\section{b. High-frequency humidity sensors}

\section{1) LYMAN- $\alpha$ HYGROMETERS}

Figure 9 illustrates the frequency response of five Lyman- $\alpha$ hygrometers (two exposed to the airstream, and three in the aspirators) operating simultaneously for a 45-min period. Frequency response is the same for all five sensors up to about $0.2 \mathrm{~Hz}$; beyond this frequency a gradual roll-off is caused by the aspirators, amounting to a factor of about 10 in the spectra (or $\sqrt{10} \approx 3$ in amplitude) at $3 \mathrm{~Hz}$ for the $\mathrm{BIO}$ refinery and the KNMI cyclone, but less than a factor of 2 in the spectrum for the UW spray flinger with its more direct flow path. This frequency response is adequate for determination of fluxes by the eddy correlation method. For inertial-dissipation flux estimates, a higher frequency response would be required.

The high mortality of Lyman- $\alpha$ sensors in previous experiments in the marine surface layer was largely avoided by use of the aspirators and frequent cleaning of the windows. The price one pays for the sensor protection is the reduced frequency response illustrated in
Fig. 9. The unprotected Lyman- $\alpha$ hygrometers did not function when water stayed on the sensor windows, in strong rains and intense fog. The IMST-SA-Riso instrument on the boom usually received about hourly cleaning with a $50 \%$ mixture of distilled water and ethyl alcohol on a cotton swab. However, even under conditions of high wind and large aerosol concentrations the high power of its source allowed it to continue measurements during several hours. The absolute sensitivity decreased with the increasing salt coating, but remained sufficient to measure the lower frequencies in the inertial subrange (those that are measured by the sonic anemometer) by using the log-sensitivity method or by determining its current sensitivity from comparison to another hygrometer (Fairall et al. 1990). At the elevation of $26 \mathrm{~m}$ the spray concentrations were much lower and the PSU-Risø instrument on the mast needed servicing only about two times a day. Once a day the windows of both instruments were polished with $0.05-\mu \mathrm{m}$ alumina powder. For a duration of 8 weeks, three sources were used for the IMST-SA-Ris $\varnothing$ instrument and four for the PSU-Risø one.

\section{2) THERMOCOUPLE PSYCHROMETERS}

Figure 10 shows an unprotected thermocouple after 30 -min exposure in moderate winds at about $7 \mathrm{~m}$ above mean sea level. The white cubes at the arrows in Figs. $10 \mathrm{a}$ and $10 \mathrm{c}$ are salt crystals remaining on the sensor following evaporation of salt water droplets deposited

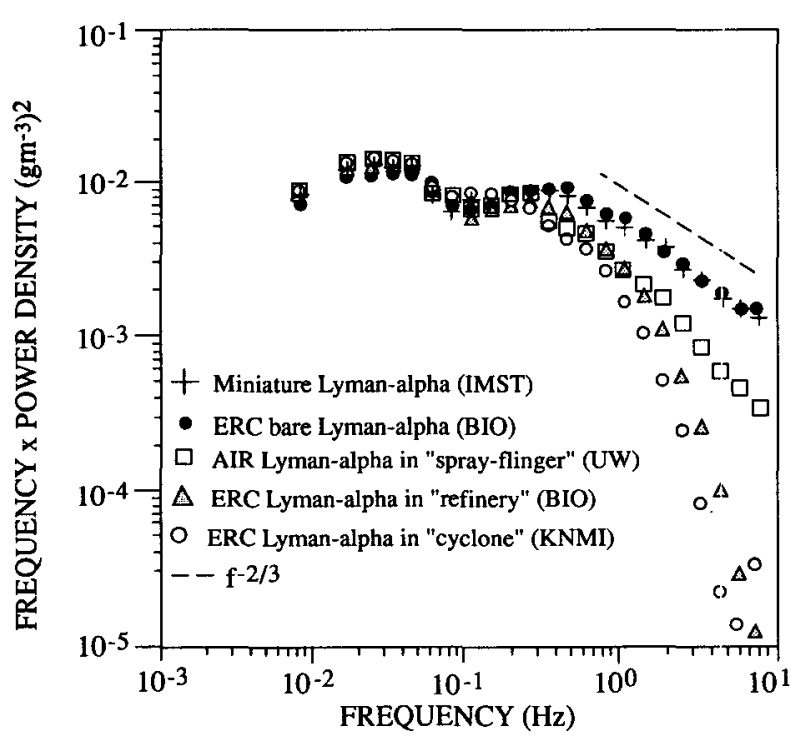

FIG. 9. Auto spectra of water vapor density collected from five Lyman- $\alpha$ hygrometers operated simultaneously during HEXMAX run BIO 304, 1620-1705 UTC. The two bare sensors (IMST-plus sign and BIO-dot) are shown to exhibit nearly a $-5 / 3$ power law above about $1 \mathrm{~Hz}$. The sensors operated inside the protective housings show a roll-off of spectral energy at the high frequencies. Symbols for IMST Lyman- $\alpha$ show bandwidths and error bars of the spectral analysis. 

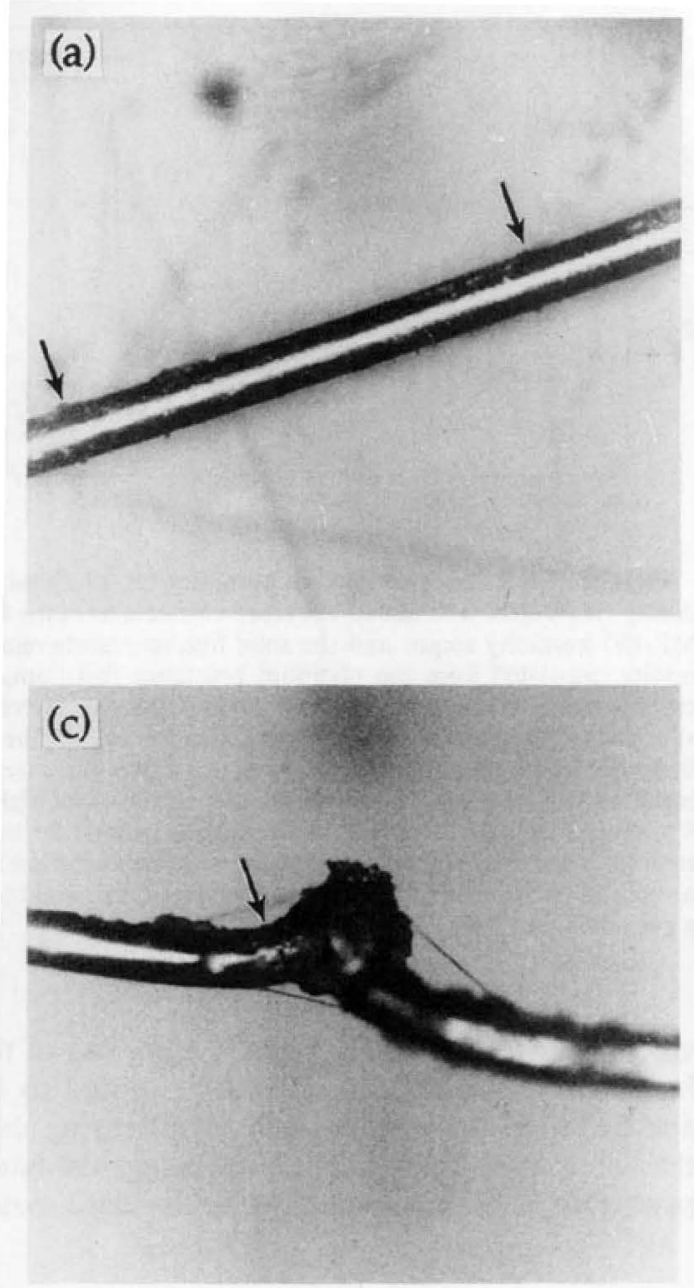
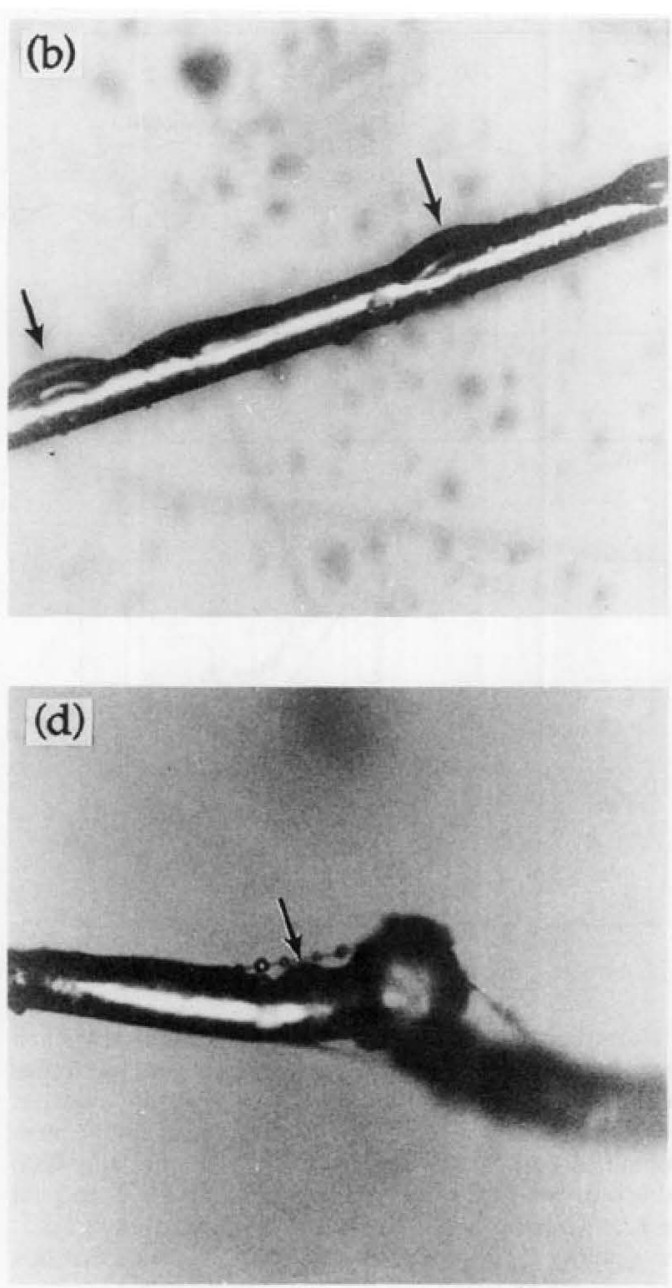

FIG. 10. Two examples of salt crystals on the dry thermocouple (no wick). In panels (a) and (c) the wires and in (c) also the thermocouple welds are clearly visible. The wires have just been put under the microscope in the dry indoor environment of MPN. In (b) and (d) the crystals have deliquesced after being breathed upon.

on the thermocouple from the airstream. Figures $10 \mathrm{~b}$ and $10 \mathrm{~d}$ show the same thermocouples moments later; as they were exposed to the high relative humidity of human breath the crystals have deliquesced into droplets. Thermocouples housed in the aspirated protective units were much less prone to this contamination problem, and in addition they were rinsed and replaced at regular intervals. The rinsing did not remove all the salt particles, suggesting a chemical bonding to the oxidized parts of the metals. Exposed sensors may also be at risk for soot contamination from long-lived particles produced over land or from ship or platform exhaust.

\section{3) HICUP DEVICE}

Time series and power spectra of the experimental HICUP device and a Michell cooled-mirror dewpoint hygrometer (Figs. 11) operated on the bow of RRS Frederick Russell show good general agreement between the two instruments. However, during the early stages of the cruise, the thermoelectric cooling modules were unable to cope with the demands made upon them when a period of sunny weather with low relative humidities was encountered. Consequently, the reference humidifiers were unable to span the ambient dewpoint and the interpolation algorithms employed by HICUP. The sensor became increasingly inaccurate in extrapolating to the dewpoint from the hygristor observations, resulting in a significant offset between the HICUP and Michell observations (Fig. 11a). Nevertheless, there is good temporal agreement between the two instruments even in these extreme circumstances, suggesting that realistic power spectral densities may be derived during these episodes. 

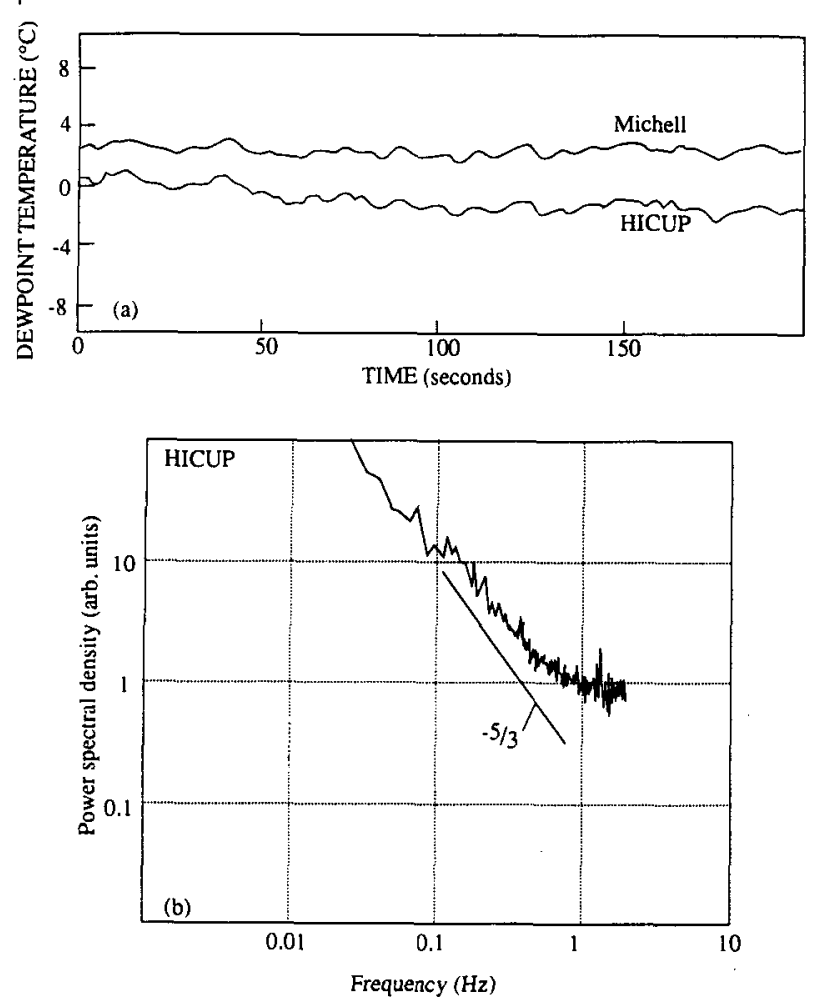

FIG. 11. Humidity obtained by a HICUP sensor and a Michell cooled-mirror device. (a) Time series of dewpoint temperatures measured with UMIST HICUP and a Michell cooled-mirror device. (b) Power spectral density of HICUP dewpoint temperature measurements obtained on 9 November 1986 between 0900 and 1000 UTC. Wind speed was $16.5 \mathrm{~m} \mathrm{~s}^{-1}$. Air temperature $10^{\circ} \mathrm{C}$ and sea temperature $12.4^{\circ} \mathrm{C}$. Mean water vapor mixing ratio $0.006 \mathrm{~kg} \mathrm{~kg}^{-1}$. Atmospheric stability $Z / L=-0.024$, where $L$ is Monin-Obukhov length.

\section{c. Low-frequency humidity sensors}

Figure 12 shows two time series of humidity at MPN for a 24-h period during HEXMAX. The humidity traces obtained from the shop-made psychrometer (using R. M. Young platinum resistance thermometers) and from the Rotronic MP- 100 device differ most at relative humidities less than $70 \%$, particularly after periods of high relative humidity. The Rotronic MP100 needs time to dry out after periods of high relative humidity and/or direct impact by rain. The largest differences between the two instruments occurred during the drying periods between 0600 and 1200 LST, and later when the humidity again increased between 1500 and 1700 LST, followed by a rain shower. The $8 \%$ bias in the scatter diagram of the relative humidities measured by the Rotronic MP-100 and the platinum resistance thermometer psychrometer (Fig. 13) is not simply due to calibration error but as illustrated by Fig. 12 appears to be due to hysteresis.

It may also be difficult to keep the wet bulb of a psychrometer wet, if the wick is directly exposed to

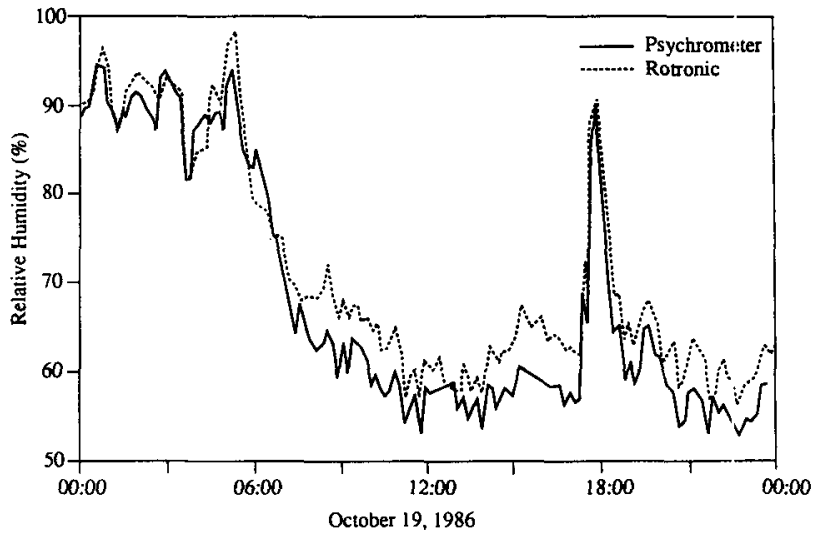

FIG. 12. Time series of relative humidity for 19 October 1986 during HEXMAX. The dotted line represents data from the Rotronic MP-100 humidity sensor and the solid line represents relative humidity calculated from the platinum resistance thermometer psychrometer dry-and wet-bulb temperatures. The sensors were located very near each other on the same corner of the MPN. The relative humidities derived from these two systems agree fairly well at the high ( $>80 \%$ ) values, but the Rotronic MP-100 is biased high (about $8 \%$ on average over the whole measurement period) for lower humidities. The Rotronic device does not seem to attain the low ambient humidities, particularly when these episodes are preceded by rain, or a period of high $\mathrm{RH}$.

very strong winds. In HEXMAX a portion of the wet bulb was unshielded and directly exposed to the air and had to be rewetted occasionally. Rinsing also kept the wick clean. By regular checking against handheld psychrometers, erroneous wet-bulb data could be

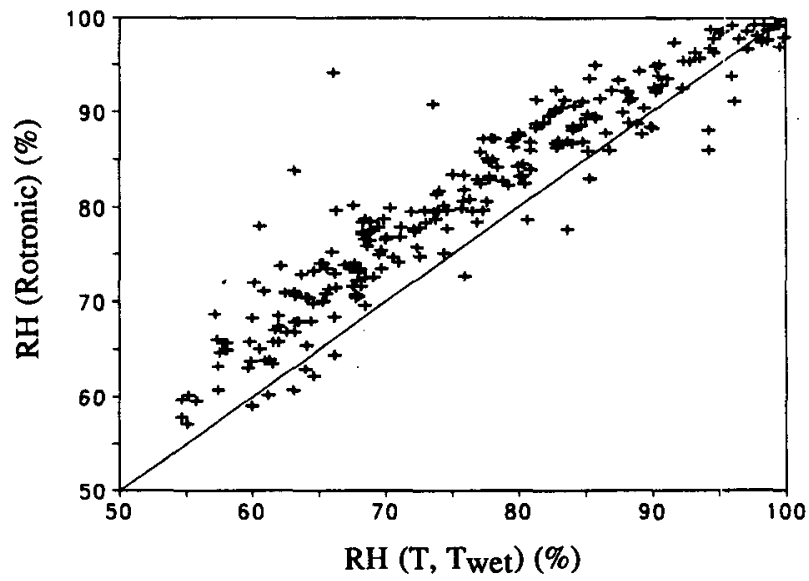

FIG. 13. Mean relative humidity measured by a shielded Ristronic MP-100 device vs the mean relative humidity derived from the resistance thermometer wet- and dry-bulb psychrometer for l-h averaging periods during HEXMAX (there are $248 \mathrm{~h}$ of comparison). The Rotronic MP-100 has an average positive bias of abcut $8 \%$, which was also verified by comparison with observations made with an aspirated mercury thermometer psychrometer. The best fit to these data $(r=0.94$ for 248 points) used to calculate relative humidity when the psychrometer was not working is $\mathrm{RH}(\%)=1.05$ (Rotronic). -8.4 . 
identified and removed. The psychrometer of the If $M$ instrumented mast at the tripod had been used at sea before. Good agreement between fast- and slow-response psychrometers was obtained.

\section{d. High-frequency temperature sensors}

In spite of all the effort to protect sensors, our HEXMAX experience showed that it was even more difficult to obtain adequate measurement of heat flux (i.e., highfrequency temperature fluctuations) than evaporation rate (high-frequency humidity fluctuations) (DeCosmo et al. 1994). Part of the reason was that the air-sea temperature difference was rather small, of the order of $2^{\circ} \mathrm{C}$ or less in HEXMAX most of the time, so that the fluctuating temperature signal was very small, and for some systems the signal-to-noise ratio was not optimal.

The use of temperature fluctuation signals derived from fluctuations in the speed of sound are particularly attractive for studies in the marine surface layer since in principle this noncontact method eliminates the problem of salt contamination. Two corrections are necessary (Kaimal and Gaynor 1991; Larsen et al. 1993): adjustments for the increase in the travel time along a vertical path due to horizontal wind, and for the influence of humidity on the speed of sound. Both of these are based on well-known principles and can be part of a computer-based time series data system with horizontal wind and humidity also available. [In fact the sensitivity to humidity is for some purposes an advantage, since the "sound virtual temperature" includes about $80 \%$ of the influence of humidity on the density stratification (see Edson et al. 1991).] The Kaijo Denki sonic anemometer-thermometers used in
HEXMAX employ sequential upward and downward pulses between the same transducers to sense the vertical wind and the temperature. Velocity contamination of the temperature channel obscures the measured uncorrected temperature spectrum at frequencies above $2 \mathrm{~Hz}$ (Fig. 14), even with a relatively large sea-air temperature difference of $3.8^{\circ} \mathrm{C}$. A third correction is required for errors in temperature caused by variations in vertical wind between the times of the pulses. With appropriate corrections applied, the sonic temperature spectrum can be extended to give values in the inertial subrange (Larsen et al. 1993).

In spite of the difficulties in interpreting the temperature data from the Kaijo Denki sonic instrument, the HEXIST group obtained heat flux estimates from this instrument using a somewhat cumbersome data analysis (Edson et al. 1991). Comparison between covariance and inertial-dissipation estimates shows good agreement and although the analysis method is somewhat complex (Larsen et al. 1993), the reliability of the methods used seems quite convincing. The limitations of currently available sonic anemometers could in principle be overcome. It can be hoped that a manufacturer will pay attention to this problem and will produce an instrument that will measure the temperature fluctuations as precisely as the velocity fluctuations.

Confirming the conclusions of Schmitt et al. (1978), the cold-wire thermometer was soon contaminated by salt when operated unprotected at only $6 \mathrm{~m}$ over the sea surface in strong winds, although the $5-\mu \mathrm{m}$ sensing wires recovered well after rinsing in distilled water. Therefore, this sensor was used mainly as a control immediately after maintenance to check the effective frequency response of the other sensors, and occasion-
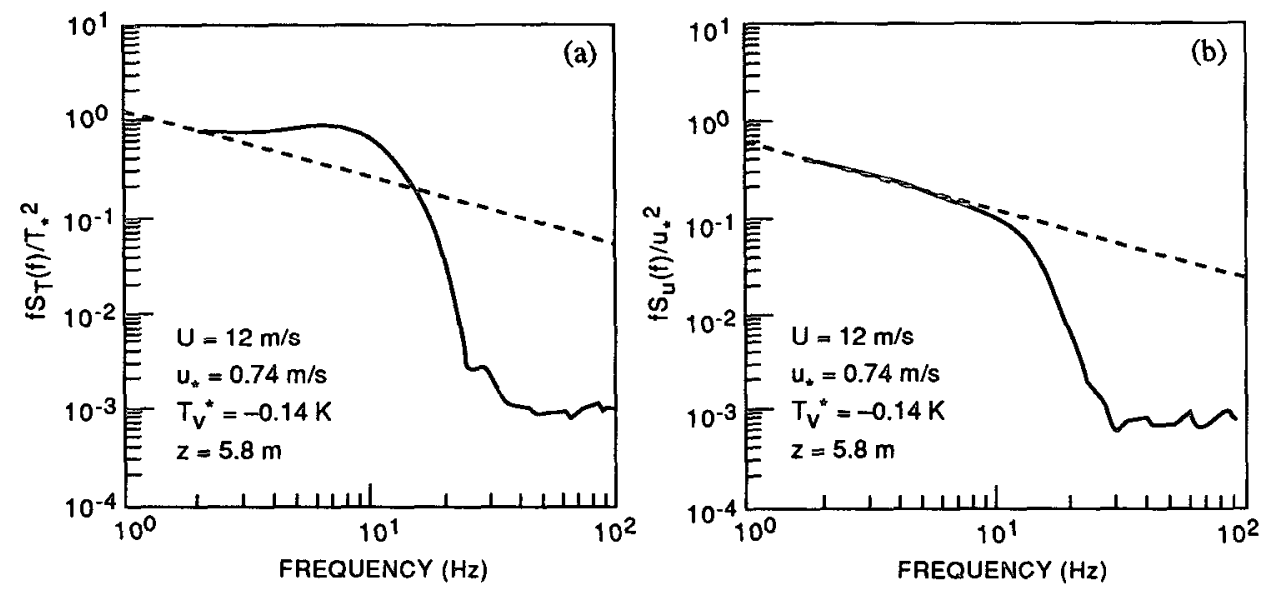

FIG. 14. Typical measured spectra of (a) sonic temperature, and (b) horizontal velocity obtained during HEXMAX. The spectra clearly show a low-pass filter with a $3-\mathrm{dB}$ frequency around $10 \mathrm{~Hz}$ and just as clearly the absence of a distinct inertial subrange for the temperature spectrum. The inertial subrange slope of $-2 / 3$ is indicated by the broken lines. Here, $T_{*}$ and $T_{v^{*}}$ are the scaling parameters for temperature and virtual temperature. The data are from 24 October 1986. 
ally to obtain direct reference dissipation rates. Its signal was also processed routinely to obtain inertial-dissipation and covariance fluxes. The salt contamination error was indeed rather large on the cold-wire inertialdissipation estimates, but surprisingly small (relative to Schmitt et al. 1978) on the covariance estimates. This result is probably a tribute to the nearly hourly cleaning or replacement of the cold-wire sensors (Fairall et al. 1990).

\section{e. Thermistors}

Comparison of temperature spectra obtained with two simultaneously sampled fast response thermistors is found in Fig. 15; the microbead spectrum agrees with the Fastip at frequencies below $0.05 \mathrm{~Hz}$ but departs from the expected $f^{-5 / 3}$ spectral shape in the inertial subrange of frequencies. Similar symptoms were occasionally seen in the Fastip response, but it was much less vulnerable to contamination. These spectral distortions did not occur when microbead thermistors were used in an earlier marine experiment (Smith 1980). In that experiment the sensors were shielded except during data-logging periods, and were at a higher level $(13 \mathrm{~m})$ over the North Atlantic Ocean in winter, where humidity fluctuations were usually small and rinsing by rain was frequent.

\section{f. Low-frequency temperature sensors}

The R. M. Young aspirated platinum resistance thermometer performed very well. When compared to

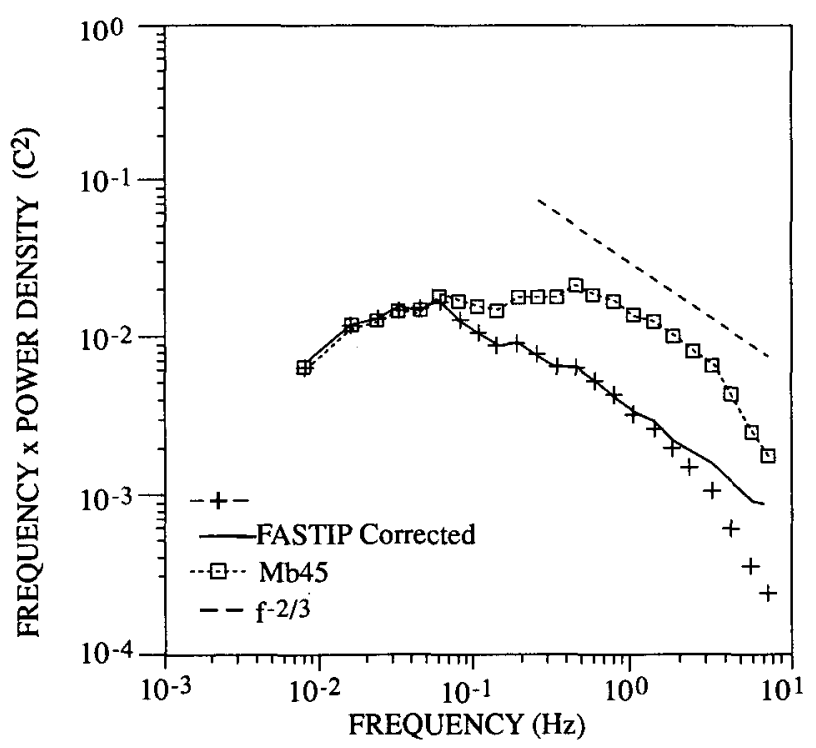

FIG. 15. Temperature spectra from Fastip $(\square)$ and microbead $(+)$ thermistors, BIO run 68,0358 UTC 23 October 1986 . Wind speed was $12.6 \mathrm{~m} \mathrm{~s}^{-1}$; sea-air temperature difference $3.8^{\circ} \mathrm{C}$. Dashed line is $f^{-5 / 3}$ spectral power law as predicted for inertial subrange. Fastip spectrum compensated for spectral roll-off with a time constant of $0.035 \mathrm{~s}$ (solid line) matches this slope; higher microbead spectral values above $0.1 \mathrm{~Hz}$ are believed to be due to salt contamination.

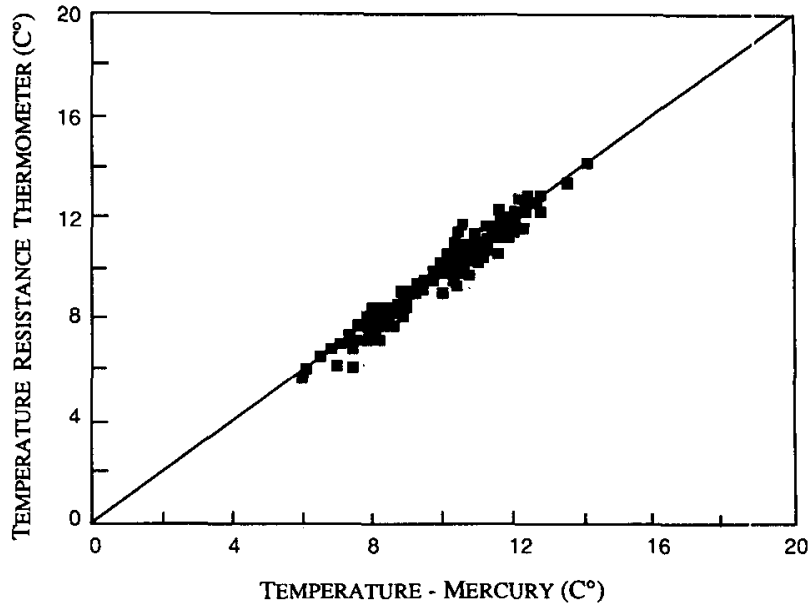

FIG. 16. R. M. Young platinum resistance thermometer temperature reading vs hand-held mercury-in-glass psychrometer ternperature.

the mercury-in-glass or the hand-held Jenway sensors, the bias was less than $0.5^{\circ} \mathrm{C}$ with the hand-held sensors reading high with standard rms errors of $0.3^{\circ} \mathrm{C}$. Some of this error, perhaps most of it, is due to human reading difficulties and faulty exposure of the hand-held sensors. Figure 16 illustrates this relationship. Similarly the If $\mathbf{M}$ resistance thermometer performed well.

\section{Conclusions and discussion}

It is possible to measure mean and fluctuating temperature and humidity in high wind conditions over the sea, but not without special precautions. Both the psychrometric technique, employing fine-wire thermocouples, and a Lyman- $\alpha$ hygrometer worked well in their protective housing for measuring fluctuating temperature and humidity. Furthermore, the frequency response of all fast-response temperature and humidity sensors in the protective housings remained adequate, so that, in conjunction with a high-frequency vertical velocity signal, turbulent fluxes of heat and water vapor could be accurately determined by the eddy correlation method. Several electronic psychrometers in radiation shields with natural or forced ventilation performed well for measuring the mean values of temperature and humidity. Wylie and Lalas (1985) have reevaluated the constants in the psychrometric equation and state that psychrometers, if free from organic film contaminants, can achieve accuracy of $0.1 \%$ in $\mathrm{RH}$. Good agreement between the Rotronic MP-100 and psychrometric mean relative humidity values during periods of ideal conditions for both methods is an argument for their validity (but of course still dependent on the inherent accuracy of calibration methods for both types of sensors). ,For unattended operation a peristaltic pump may be required to keep the wet bulb flushed, as was used by If $M$ on the tripod. In a winter 
experiment [the Surface Wave Dynamics Experiment (SWADE), 1991 ] similar psychrometers were operated unattended high on a ship for several weeks without the wet bulb drying out. No part of the wet-bulb wick was outside the shield and a copper or brass object in the water container kept algae from growing in the water supply.

The Rotronic MP-100 capacitance sensor worked continuously and relatively well thanks to the Gortex filters employed (van der Meulen 1988). After rain or very high relative humidities the Rotronic MP-100 showed hysteresis. We believe that such humidity sensors cannot be employed at low elevations from ordinary meteorological buoys because the humidity of the air penetrating a protective filter would be modified by spray and moist salt deposited on it. Any type of system would need regular automatic cleansing.

The HICUP shows promise as an instrument for use in the marine environment. Increased cooling power would ensure that the calibration cells were capable of straddling the ambient dewpoint under most oceanic conditions, while improvements to the signal conditioning should result in a frequency response sufficient for determining vapor fluxes by the dissipation techniques.

The Lyman- $\alpha$ hygrometers worked well for highfrequency humidity fluctuations but required frequent maintenance and calibration. The useful operating time was substantially extended by the use of an aspirator, and operations during periods of rain were possible. The miniature Lyman- $\alpha$ of Mestayer et al. (1989) should be used for specialized investigations to take advantage of the streamlined airflow around it and therefore its ability to measure very small scales. These advantages are lost inside aspirators. It can be exposed only in favorable conditions (moderate wind speeds and no precipitation or fog). There is good hope that fast infrared hygrometers that are currently available and used on land will soon become reliable alternative instruments for fast humidity measurements in the marine environment (e.g., Fairall and Young 1991).

Using a sonic anemometer for temperature measurements in the marine environment has great appeal because it is a noncontact method and should therefore be less sensitive to sea spray in the air. During HEXMAX the method was used with some success, although sonic anemometers do not function well when their transducers are wet; this may be due to some combination of acoustic influence at the probe tips and leakage of the high voltages used to drive the transducers. Currently available instruments are not particularly well designed for temperature measurements and require complex analysis. Specially designed sonic devices and analysis software are needed for this technique to become routine, and a side-by-side humidity measurement would also be required. For scientific questions where the virtual temperature is the desired parameter, the sonic anemometer could provide it directly (Kaimal and Gaynor 1991).

We recognized at the outset that to meet the HEXOS objectives of deriving water vapor and heat flux parameterizations applicable for whitecap sea states, special precautions were required. Devices had to be designed to remove sea spray from the airstream and many checks and tests had to be built into the procedures, because sea salt aerosols are very destructive to humidity and temperature sensors. The ultimate success of the project as evidenced by the joint scientific articles listed in the introduction, depended to a large extent on the redundancy provided by several groups measuring the same parameter with different techniques. Because of the duplication of sensors and the many intercomparisons reported in this article, in addition to the great good fortune of having the desired weather conditions for many hours of data collection, we are able to present the flux and parameterization results with confidence (DeCosmo et al. 1994).

Acknowledgments. The authors gratefully acknowledge the following support. The three lead authors and S. E. Larsen were supported for HEXOS work by Grant N00014-85-K-0123 (HEXOS) from the Office of Naval Research, Marine Meteorology Program, and in the initial stages by NSF Grant R11-8310351. We appreciate the assistance of S. S. Ataktürk in the data collection. The contribution by the If $M$ group was supported by the Deutsche Forschungsgemeinschaft within SFB 133. During most of the HEXOS program, P. G. Mestayer was working at the IMST, Marseille, France, and was supported by the Institut National des Sciences de l'Univers du CNRS under Grant PAM 56-67. He wishes to express his gratitude to his colleagues at IMST, especially to Bertrand Zucchini, who participated in HEXMAX on MPN, to Florence Goutail and colleagues at the Service d'Aéronomic du CNRS, who participated in the construction of the hygrometer, and also to HEXIST group buddies Chris Fairall and Jim Edson. HICUP was designed and developed by C. S. Mill and constructed by P. Kelly. Assistance with the ship measurements was provided by P. M. Park and M. K. Hill, and the data analysis was performed by I. E. Consterdine. To these colleagues M. H. Smith expresses his gratitude, and he wishes to thank the U.K. Natural Environmental Research Council for the provision of ship time and support under Grant GR3/ 6267. G. de Leeuw participated in the HEXOS programme in the framework of assignment A86/KM/ 103 by the Royal Netherlands Navy, while support for the HEXMAX experiments was received as TNO "doelsubsidie." He expresses his gratitude to colleagues at TNO for support both during preparation of the experiments and in the analysis. All the contributors appreciate the important support provided by the North Atlantic Treaty Organization for planning and data analysis workshops. The support of the HEXOS 
program by KNMI and the Rijkswaterstaat, which operates Meetpost Noordwijk, is gratefully acknowledged. The technical assistance for operating Meetpost Noordwijk provided by Jan Schaap, Ed Worrel, and Cor van Oort was much appreciated by all.

\section{REFERENCES}

Anderson, R. J., and S. D. Smith, 1981: Evaporation coefficient for the sea surface from eddy flux measurements. J. Geophys. Res., 86, 449-456.

Ataktürk, S. S., and K. B. Katsaros, 1989: K-Gill: A twin propellorvane anemometer for measurement of atmospheric turbulence. J. Atmos. Oceanic Technol., 6, 509-515.

Blanc, T. V., 1985: Variation of bulk-derived surface flux, stability, and surface roughness results due to the use of different transfer coefficient schemes. J. Phys. Oceanogr., 15, 650-669.

- 1987: Accuracy of bulk-method-determined flux, stability, and sea surface roughness. J. Geophys. Res., 92, 3867-3876.

Bortkovskii, R. S., 1987: Air-Sea Exchange of Heat and Moisture during Storms. Reidel, $194 \mathrm{pp}$.

Buck, A. L., 1985: The Lyman-alpha absorption hygrometer. Moisture and Humidity, Instrument Society of America, 411-436.

Busch, N. E., 1972: On the mechanics of atmospheric turbulence. Workshop on Micrometeorology, Boston, MA, Amer. Meteor. Soc., 1-65.

Chahuneau, F., R. L. Desjardins, E. Brach, and R. Verdon, 1989: A micrometeorological facility for eddy flux measurements of $\mathrm{CO}_{2}$ and $\mathrm{H}_{2} \mathrm{O}$. J. Atmos. Oceanic Technol., 6, 193-200.

Coantic, M., and C. A. Friehe, 1980: Slow-response humidity sensors. Air-Sea Interaction, Instruments and Methods, F. Dobson, L. Hasse, and R. Davis, Eds., Plenum Press, 399-411.

Deacon, E. C., 1980: Slow-response temperature sensors. Air-Sea Interaction, Instruments and Methods, F. Dobson, L. Hasse, and R. Davis, Eds., Plenum Press, 255-267.

DeCosmo, J., 1991: Air-sea exchange of momentum, heat, and water vapor over whitecap sea states. Ph.D. thesis, University of Washington, Seattle, WA, $212 \mathrm{pp}$. [Available from Dept. of Atmospheric Sciences, University of Washington, Seattle, WA 98195.]

—, K. B. Katsaros, S. D. Smith, R. J. Anderson, W. Oost, K. Bumke, and A. L. M. Grant, 1994: Air-sea exchange of sensible heat and water vapor over whitecap sea states. J. Geophys. Res. Oceans, in press.

de Leeuw, G., 1989: Investigations on turbulent fluctuations of particle concentrations and relative humidity in the marine atmospheric surface layer. J. Geophys. Res., 94, 3261-3269.

butions and relative humidity in the atmospheric surface layer over the North Sea. Tellus, 42B, 342-354.

Edson, J. B., 1989: Langrangian model simulations of the turbulent transport of evaporating jet droplets. Ph.D. thesis, The Pennsylvania State University, $141 \mathrm{pp}$. [Available from Department of Meteorology, The Pennsylvania State University, University Park, PA 16802.]

- C. W. Fairall, P. G. Mestayer, and S. E. Larsen, 1991: A study of the inertial-dissipation method for computing air-sea fluxes. J. Geophys. Res., 96, 10 689-10 711.

Fairall, C. W., and S. E. Larsen, 1986: Inertial dissipation methods and turbulent fluxes at the air-ocean interface. Bound.-Layer Meteor., 34, 287-301.

- and G. S. Young, 1991: A field evaluation of shipboard performance of an infrared hygrometer. Seventh Symp. on Meteorological Observations and Instruments. Special Sessions on Laser Atmospheric Studies, New Orleans, LA, Amer. Meteor. Soc. and WMO, 311-315.

__ J. B. Edson, S. E. Larsen, and P. G. Mestayer, 1990: Inertial dissipation of air sea flux measurements: A prototype system using real time spectral computations. J. Atmos. Oceanic Technol., 7, 425-453.
Friehe, C. A., 1993: Sensible heat flux errors from salt contamirated temperature sensors. Proc. I8th Int. Assoc. for the Physicai Sci. ences of the Oceans, Vienna, Austria, IUGG, 240.

Hasse, L., M. Grunewald, J. Wucknitz, M. Dunckel, and D. Schreiver, 1978: Profile derived turbulent fluxes in the surface layer under disturbed and undisturbed conditions during GATE. "Meteor" Forschungsergeb., Reihe B, 13, 24-40.

Hartmann, J., J. Hacker, and H. Kraus, 1990: Correction of data from a salt-spray contaminated temperature sensor. Bound.Layer Meteor., 50, 153-169.

Hay, D. R., 1980: Fast-response humidity sensors. Air-Sea Interaction, Instruments and Methods, F. Dobson, L. Hasse, and R. Davis, Eds., Plenum Press, 413-432.

Jacobs, W. C., 1942: On the energy exchange between sea and atmosphere. J. Mar. Res., 5, 36-66.

Kaimal, J. C., and J. E. Gaynor, 1991: Another look at sonic thermometry. Bound.-Layer Meteor., 56, 401-410.

- , S. D. Smith, and W. A. Oost, 1987: HEXOS-Humidity Exchange over the Sea: A program for research on water vapor and droplet fluxes from sea to air at moderate to high wind speeds. Bull. Amer. Meteor. Soc., 68, 466-476.

Katsaros, K. B., and J. DeCosmo, 1993: Water vapor flux from the sea at high wind speeds. Proc. ICSU/WMO Int. Symp. on Tropical Cyclone Disasters, Beijing, China, ICSU/WMO 386-392.

Kruspe, G., 1977: On moisture flux parameterization. Bound--Layer Meteor., 11, 55-63.

Large, W. G., and S. Pond, 1982: Sensible and latent heat flux measurements over the ocean. J. Phys. Oceanogr., 12, 464-482.

Larsen, S. E., J. Hojstrup, and C. H. Gibson, 1980: Fast-response temperature sensors. Air-Sea Interaction, Instruments and Methods, F. Dobson, L. Hasse, and R. Davis, Eds., Plenum Press, 269-292.

—, J. B. Edson, C. W. Fairall, and P. G. Mestayer, 1993: Measurement of temperature spectra by a sonic anemometer. $J$. Atmos. Oceanic Technol., 10, 345-354.

Ling, S. C., and T. W. Kao, 1976: Parameterization of the moisture and heat transfer process over the ocean under whitecap sea states. J. Phys. Oceanogr., 6, 306-315.

Mestayer, P. G., F. Goutail, and S. E. Larsen, 1989: Improved Lvmanalpha humidiometer. Part III: Performance of a field version for small-scale atmospheric turbulence measurements over the sea. Rev. Sci. Instrum., 60, 121-126.

—_ J. B. Edson, M. P. Rouault, C. W. Fairall, S. E. Larsen, G. de Leeuw, D. E. Spiel, J. DeCosmo, K. B. Katsaros, E. C. Monahan, R. Schiestel, 1990: CLUSE simulations of vapor flux transformations by droplet evaporation. Proc. Workshop on Modelling the Fate and Influence of Marine Spray, Luminy, Marseille, France, Marine Sciences Institute, University of Connecticut, $100-105$.

Oost, W. A., E. H. W. Worrell, J. W. Schaap, C. van Oord, and C. Kraan, 1991: An improved version of the pressure anemometer. J. Atmos. Oceanic Technol., 8, 331-340.

- C. C. W. Fairall, J. B. Edson, S. D. Smith, R. J. Anderson, J. A. M. Wills, K. B. Katsaros, and J. DeCosmo, 1994: Flow distortion calculations and their application in HEXMAX. $J$. Atmos. Oceanic Technol., 11, 366-386.

Rouault, M. P., P. G. Mestayer, and R. Schiestel, 1991: A model of evaporating spray droplet dispersion. J. Geophys. Res., 96, $7181-$ 7200 .

Schmitt, K. F., C. A. Friehe, and C. H. Gibson, 1978: Humidity sensitivity of atmospheric temperature sensors by salt contamination. $J$. Phys. Oceanogr., 8, 151-161.

Schmugge, T. J., and J. C. Andre, Eds., 1991: Land Surface Evaporation, Measurement and Parameterization. Springer-Verlag, $424 \mathrm{pp}$.

Shaw, W. J., and J. E. Tillman, 1980: The effect of and correction for different wet-bulb and dry-bulb response in thermocouple psychrometry. J. Appl. Meteor., 19, 90-97.

Smith, S. D., 1980: Wind stress and heat flux over the ocean in gale force winds. J. Phys. Oceanogr., 10, 709-726. 
- 1989 : Water vapor fluxes at the sea surface, a review. Bound.Layer Meteor., 47, 227-293.

- 1990: Influence of droplet evaporation on HEXOS humidity and temperature profiles. Proc. Workshop on Modelling the Fate and Influence of Marine Spray, Luminy, Marseille, France, Marine Sciences Institute, University of Connecticut, $171-174$.

- - and R. J. Anderson, 1984: Spectra of humidity, temperature and wind over the sea at Sable Island, Nova Scotia. J. Geophys. Res., 89, 2029-2040.

- K. B. Katsaros, W. A. Oost, and P. Mestayer, 1990: Two major experiments in the Humidity Exchange over the Sea (HEXOS) program. Bull. Amer. Meteor. Soc., 71, 161-172.

$\longrightarrow$, R. J. Anderson, W. A. Oost, C. Kraan, N. Maat, J. DeCosmo, K. B. Katsaros, K. Bumke, L. Hasse, K. L. Davidson, and H. M. Chadwick, 1992: Sea surface wind stress and drag coefficients: The HEXOS results. Bound.-Layer Meteor., 60, 109142.
Stramska, M., 1987: Vertical profiles of sea salt aerosol in the atmosphere surface layer: A numerical model. Acta Geophysica Polonica, 35, 87-99.

Tillman, J. E., 1991: In situ water vapor measurements in the Lymanalpha and infrared spectrum: Theory and components. Land Surface Evaporation: Measurement and Parameterization, T. J. Schmuge and J.-C. Andre, Eds., Springer-Verlag, 313-335.

Tsukamoto, O., 1986: Dynamic response of the fine wire psychrometer for direct measurement of water vapor flux. J. Atmos. Oceanic Technol., 3, 453-461.

van der Meulen, J. P., 1988: On the need of appropriate filter techniques to be considered using electrical humidity sensors. Proc. WMO Technical Conf. on Instruments and Methods of Observation (TECO-1988), Leipzig, Germany, WMO, 55-60.

Wylie, R. G., and T. Lalas, 1985: Accurate psychrometer coefficients for wet and ice covered cylinders in laminar transverse air streams. Proc. Moisture and Humidity, 1985. Measurement and Control in Science and Industry, Washington, DC, Instrument Society of America, 37-56. 